\title{
Contribution to the knowledge of the Clytrini of the Eastern Mediterranean, the Near East and the Arabian Peninsula, with descriptions of four new species (Coleoptera: Chrysomelidae: Cryptocephalinae)
}

\author{
Jan BEZDĚK ${ }^{1, *}$ \\ ${ }^{1}$ Department of Zoology, Fisheries, Hydrobiology and Apiculture, Mendel University in Brno, \\ Zemědělská 1, CZ-613 00 Brno, Czech Republic. \\ *Corresponding author: bezdek@mendelu.cz \\ ${ }^{1}$ urn:lsid:zoobank.org:author:668F3A35-3E6E-40F3-9F06-356EEB50E45F
}

\begin{abstract}
Four new species of the tribe Clytrini Kirby, 1837, Labidostomis bcharrensis sp. nov. (Lebanon), Tituboea friedmani sp. nov. (Israel), Tituboea harteni sp. nov. (United Arab Emirates) and Tituboea radeki sp. nov. (Yemen, Oman), and the formerly unknown females of Labidostomis damavandensis Rapilly, 1984 and Saudiclytra wittmeri Medvedev, 1979 are described. The following new synonyms are proposed: Coptocephala coptocephaloides (Lacordaire, 1848) = Coptocephala furthi Medvedev, 1992 syn. nov., Labidostomis rufa (Waltl, 1838) = Labidostomis rufa (Lacordaire, 1848) syn. nov., Tituboea olivieri (Lacordaire, 1848) = Tituboea femoralis Medvedev, 1962 syn. nov., Saudiclytra wittmeri (Medvedev, 1979) = Saudiclytra spinifemorata Medvedev, El Torkey \& Al Dhafer, 2014 syn. nov. A neotype is designated for Clythra (Tituboea) olivieri Lacordaire, 1848. Tituboea decemguttata Walker, 1871 is considered as nomen dubium. The variability of the elytral pattern of Afrophthalma arabica (Bryant, 1957) is delimited. New country records and comments on distribution of Clytrini species from the eastern Mediterranean, the Near East and the Arabian Peninsula are presented.
\end{abstract}

Keywords. Arabian Peninsula, Near East, new synonymy, Mediterranean, taxonomy.

Bezděk J. 2018. Contribution to the knowledge of the Clytrini of the Eastern Mediterranean, the Near East and the Arabian Peninsula, with descriptions of four new species (Coleoptera: Chrysomelidae: Cryptocephalinae). European Journal of Taxonomy 481: 1-37. https://doi.org/10.5852/ejt.2018.481

\section{Introduction}

The tribe Clytrini Kirby, 1837 is one of the most popular groups amongst entomologists. However, many groups within Clytrini badly need a modern taxonomic revision. The taxonomy of the whole Cryptocephalinae Gyllenhal, 1813 is complicated due to the considerable variability of colouration and the unresolved status of varieties described prior to 1960. In Clytrini itself, there are additional problematic topics such as a wide range of body lengths, male characters strongly developed in large males and less developed in smaller ones, or the formation of local populations. Many local forms 
have been described as varieties, which can be problematic since they can be ascribed to either colour aberrations or true species (Bezděk \& Regalin 2015).

In arid areas of the western Palaearctic, many species of Clytrini are very rarely collected. The publication of modern taxonomic revisions of such taxa usually requires the accumulation of material from many institutions and collections. In the last decade, only a few papers on Clytrini based on the examination of primary type material have been published (e.g., Medvedev et al. 2014; Romantsov 2017; Bezděk 2016, 2018). Western Palaearctic Clytrini taxa described by Maurice Pic and Louis Kocher were revised by Bezděk \& Regalin (2015).

During the examination of extensive material from various collections I discovered four new species described below. The formerly unknown females of Labidostomis damavandensis Rapilly, 1984 and Saudiclytra wittmeri Medvedev, 1979 are also described. In connection with the preparation of the new edition of the Palaearctic catalogue of Chrysomelidae, I have supplemented this paper with a faunistic section, where some new country records of Clytrini are presented.

\section{Material and methods}

All measurements were made using an ocular grid mounted on MBS-10 stereo microscope (at $16 \times$ magnification for the body length and $32 \times$ magnification for the remaining measurements). Photographs of almost all the specimens were taken with Canon EOS 550D digital camera with Canon MP-E $65 \mathrm{~mm}$ objective. Images of the same specimen at different focal planes were combined using Helicon Focus 5.3 software.

The exact label data are cited for all type specimens; a double slash (//) divides the data on different labels and a single slash (/) divides the data in different rows. Type localities are cited in the original spelling. Other comments and remarks are placed in square brackets: $[\mathrm{p}]=$ preceding data are printed, $[\mathrm{h}]=$ preceding data are handwritten, $[\mathrm{w}]=$ white label, $[\mathrm{r}]=$ red label, $[\mathrm{g}]=$ green label .

The terminus technicus 'kotpresse' means the rectal apparatus for forming the faecal pellets covering the eggs.

\begin{tabular}{|c|c|c|}
\hline \multicolumn{3}{|c|}{ Abbreviations for institutions and collections } \\
\hline BMNH & $=$ & The Natural History Museum, London, UK (Michael Geiser, Maxwell V.L. Barclay) \\
\hline CIUC & $=$ & $\begin{array}{l}\text { Centro Interdipartimentale dell'Università, Museo di Storia Naturale e del Territorio, } \\
\text { Calci, Italy (Marco Dellacasa) }\end{array}$ \\
\hline HNHM & $=$ & Hungarian Natural History Museum, Budapest, Hungary (Ottó Merkl) \\
\hline ISNB & $=$ & Institut royal des Sciences naturelles de Belgique, Brussels, Belgium (Pol Limbourg) \\
\hline JBCB & $=$ & Jan Bezděk collection, Brno, Czech Republic \\
\hline $\mathrm{JPCH}$ & $=$ & Jan Pelikán collection, Hradec Králové, Czech Republic \\
\hline KSMA & $=$ & $\begin{array}{l}\text { King Saud University, Museum of Arthropods, Riyadh, Saudi Arabia (Ashraf M. } \\
\text { El-Torkey, Hathal M. Al Dhafer) }\end{array}$ \\
\hline LMRM & $=$ & Lev N. Medvedev collection, Moscow, Russia \\
\hline LSCP & $=$ & Lukáš Sekerka collection, Prague, Czech Republic \\
\hline MNHN & $=$ & Museum national d'Histoire naturelle, Paris, France (Antoine Mantilleri) \\
\hline MZCK & $=$ & Miroslav Zúber collection, Kosmonosy, Czech Republic \\
\hline NMPC & $=$ & Národní Muzeum, Praha, Czech Republic (Jiří Hájek, Lukáš Sekerka) \\
\hline RRCA & $=$ & Renato Regalin collection, Abbiategrasso, Milano, Italy \\
\hline TAU & $=$ & Tel Aviv University, Tel Aviv, Israel (Laibale Friedman) \\
\hline USNM & $=$ & $\begin{array}{l}\text { National Museum of Natural History, Smithsonian Institution, Washington DC., USA } \\
\text { (Alexander S. Konstantinov) }\end{array}$ \\
\hline
\end{tabular}


BEZDĚK J., Clytrini of the Eastern Mediterranean, the Near East and the Arabian Peninsula

ZMHB = Stiftung Museum für Naturkunde, Leibniz-Institut für Evolutions- und Biodiversitätsforschung, Berlin, Germany (Johannes Frisch, Joachim Willers)

\section{Results}

\section{Systematic treatment}

Class Hexapoda Latreille, 1825

Order Coleoptera Linnaeus, 1758

Suborder Polyphaga Emery, 1886

Superfamily Chrysomeloidea Latreille, 1802

Family Chrysomelidae Latreille, 1802

Subfamily Cryptocephalinae Gyllenhal, 1813

Tribe Clytrini Kirby, 1837

Coptocephala coptocephaloides (Lacordaire, 1848)

Clythra (Gynandrophthalma) coptocephaloides Lacordaire, 1848: 310 (original description).

Coptocephala jaechi Warchałowski, 1991: 247 (original description).

Coptocephala furthi Medvedev, 1992: 55 (original description), syn. nov.

\section{Material examined}

Type material

ISRAEL: 1 Oे, holotype of Coptocephala jaechi, "ISRAEL 14.4. / Tiberias / leg. Jäch 1986 [w, p] // Coptocephala / jaechi mihi / det. A. Warchalowski [w, p] // HOLOTYPUS [r, p]" (BMNH); 1 o 1 , paratype of Coptocephala jaechi, "Tiberias [w, p] // Coptocephala / jaechi mihi / det. A. Warchalowski [w, p] // PARATYPUS [r, p]" (BMNH).

ISRAEL: 1 + , holotype of Coptocephala furthi, "ISRAEL [p] / Kadesh Barnea / 12.IV. [h] 19 [p] 74 [h] / D. Furth [w, p] // Coptocephala / unifasciata / Scop. [w, h] // [blank red label] // HOLOTYPUS [p] / Coptocephala / furthi m. [h] / L. Medvedev det. 199 [p] 1 [w, h]” (LMRM).

UNKNOWN COUNTRY: 1 q, syntype of Coptocephala coptocephaloides, “23220 [w, p] // Mesopotam. Helf. [w, h] // Gynandrophthalma / coptocephaloides / * / Lacord. [w, p] // LECTOTYPUS / Clythra / (Gynandrophthalma) / coptocephaloides / Lacordaire, 1848 / R. Regalin des. 1996 [r, p]" (ZMHB).

\section{Other material}

EGYPT: Sinai: 2 $\widehat{\partial}$, Wadi El Gedeirat, 13 Mar. 1937, A. Rabinovitsch leg. (USNM); 1 o, Wadi UmMitla, 21 Mar. 1937, A. Rabinovitsch leg. (USNM).

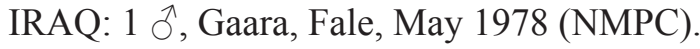

ISRAEL: 1 ภ, 1 क, NE of Arad, 7 Apr. 1981, Wewalka leg. (JBCB); 1 ภ, 2 우, Southern Negev, Har Quetura, 4 km SE of Shiz-zafon, 14 Apr. 1994, Volkovitsh and Dolgovskaya leg. (USNM); 1 , Central Negev, Makhtesh Ramon, 8-14 km NE of Mizpe Ramon, 18 Apr. 1994, Volkovitsh and Dolgovskaya leg. (USNM); 1 त̂, Southern Negev, Zafit, 25 km ESE of Dimona, 13 Apr. 1994, Volkovitsh and Dolgovskaya leg. (USNM); 1 $\widehat{\lambda}, 1$ ㅇ, Southern Negev, Zin, 14 km NW of En Hazeva, 11 Apr. 1994, Volkovitsh and Dolgovskaya leg. (USNM).

JORDAN: 1 +, Petra, 13-14 May 1995, P. Pucholt leg. (JBCB); 1 đ̆, Tabaqat, 4 May 1995, P. Pucholt

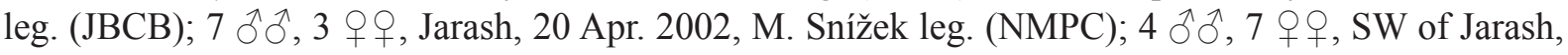


Alhuna, 12 Apr. 2009, M. Snížek leg. (JBCB); 11 đ̊̊, 8 우, Zai N. P., 30 km NW of Amman, 3206,7’ N, $35^{\circ} 34,6^{\prime}$ E, 6 May 2006, F. Kantner and L. Kantner leg. (NMPC); 11 § $\delta^{2}, 8$ 웅, $20 \mathrm{~km} \mathrm{NNW}$ of Al Karak, $31^{\circ} 14,7^{\prime}$ N, $35^{\circ} 42,5^{\prime}$ E, 1000 m a.s.1., 27 Apr. 2006, F. Kantner and L. Kantner leg. (NMPC); 1 ○, 3 우, Pella env., $30 \mathrm{~km} \mathrm{~W}$ of Ajlun, 32 $26,7^{\prime}$ N, $35^{\circ} 36,8^{\prime}$ E, 29 Apr. 2006, F. Kantner and L. Kantner

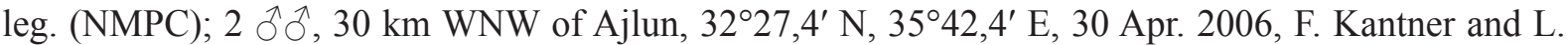

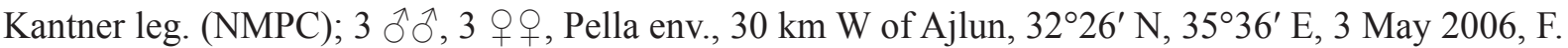

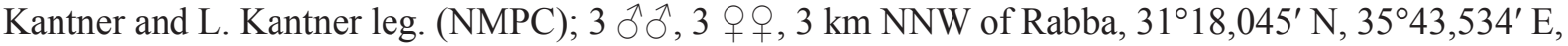
900 m a.s.l., 27 May 2007, F. Kantner and L. Kantner leg. (NMPC); 1 ô, Wadi Ramm, 12 May 1995, K. Deneš leg. (NMPC).

SYRIA: 2 ふోึ, 5 우, $17 \mathrm{~km}$ W of Dara, Wadi Al-Harir, 18-20 May 1995, J. Chaloupek leg. (JBCB);

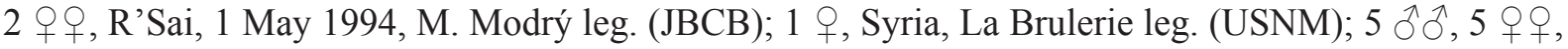

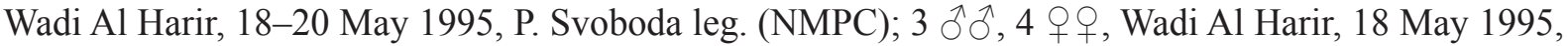
V. Němec leg. (NMPC); 1 + , Damascus env., 10 km N of Duma, 29 Mar. 1994, S. Bečváŕ leg. (NMPC).

\section{Type localities}

Clythra coptocephaloides

UNKNOWN COUNTRY: "Mesopotamie".

Coptocephala jaechi

ISRAEL: Tveriya (Tiberias).

Coptocephala furthi

ISRAEL: Hadesh Barma [Kadesh Barnea].

\section{Distribution}

Egypt, Iraq, Israel, Jordan, Sinai, Syria (Medvedev 1962; Lopatin et al. 2003; Regalin and Medvedev 2010b; present study).

\section{Comments}

Medvedev (1992) described Coptocephala furthi based on one female with strong pronotal punctures. Lopatin (2002) synonymised Coptocephala furthi with Coptocephala jaechi. Regalin \& Medvedev (2010a) synonymised Coptocephala jaechi with Coptocephala coptocephaloides and restored Coptocephala furthi as a valid species. I examined the primary type material of all three taxa, supplemented by numerous additional specimens. The pronotal punctation is very variable, usually feeble, but in some populations (primarily in females) the punctures are strong. I am convinced that all three taxa are conspecific, and I propose Coptocephala furthi as a new synonym of Coptocephala coptocephaloides.

Labidostomis bcharrensis Bezděk sp. nov. urn:lsid:zoobank.org:act:344656A5-72E6-44AC-8896-D4995BCC8308

Fig. 1

\section{Differential diagnosis}

Labidostomis bcharrensis sp. nov. is characterised by the peculiar elytral colouration with a large blackish spot covering most of the disc of each elytron including the humeral calli. A similar colouration is known in the females of Labidostomis limbata (Lacordaire, 1848) from Syria and Israel but the suture is yellow in Labidostomis bcharrensis sp. nov. while the spots are united and the suture is metallic black in females of Labidostomis limbata. The males of Labidostomis limbata have a different elytral 
colouration with separated small humeral spots (Bezděk 2018). Both species also differ in the punctation of the head pronotum (lustrous, covered with small fine punctures in Labidostomis bcharrensis sp. nov.; dull, densely covered with larger punctures in Labidostomis limbata).
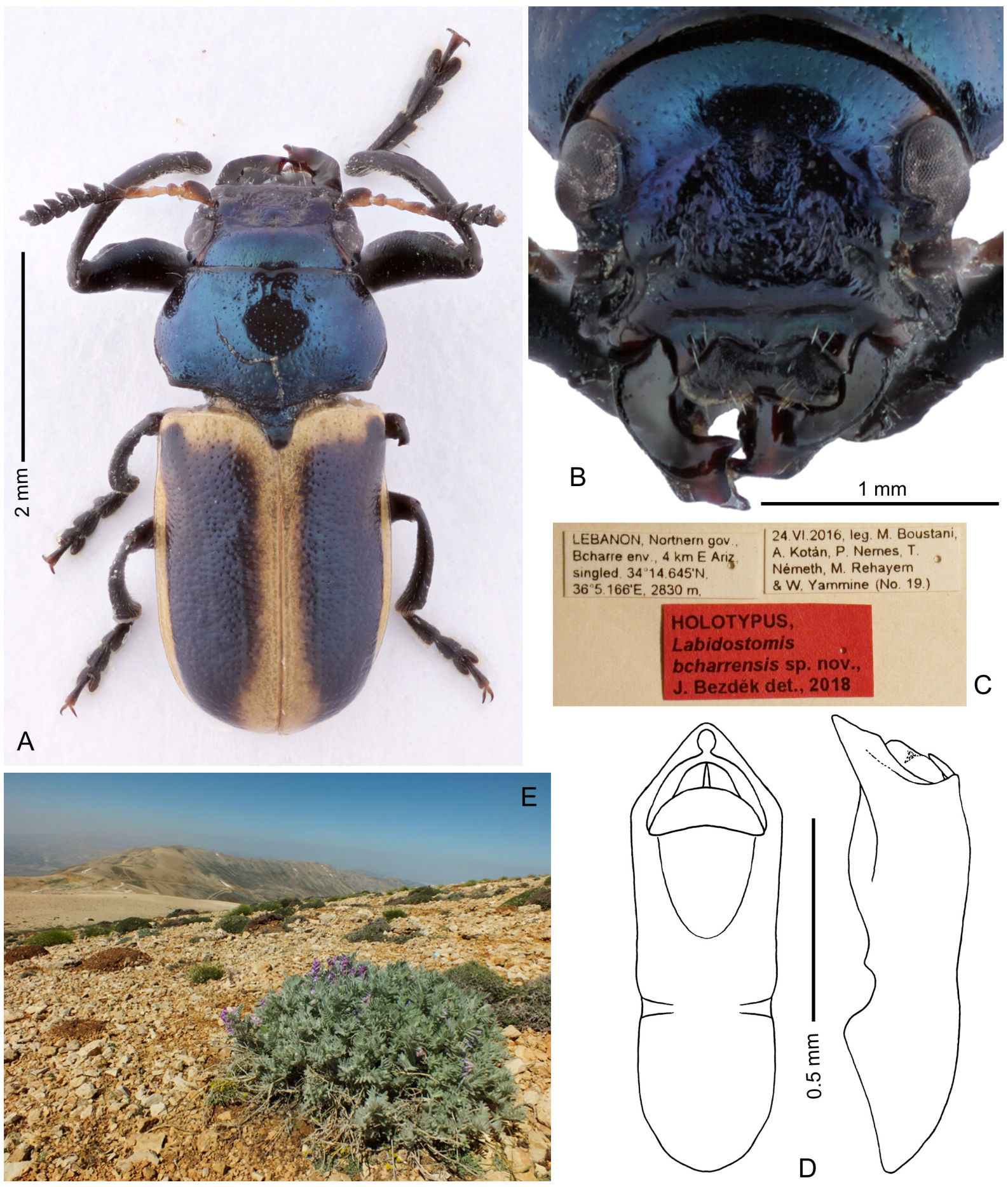

Fig. 1. Labidostomis bcharrensis Bezděk sp. nov., holotype, ô, $5.6 \mathrm{~mm}$ (HNHM). A. Dorsal view. B. Head. C. Labels. D. Aedeagus in dorsal and lateral views. E. Habitat (photo by Tamász Németh). 


\section{Etymology}

Named after the Lebanese city of Bcharre.

\section{Material examined}

\section{Holotype}

LEBANON: 1 ô, "LEBANON, Northern gov., / Bcharre env., 4 km E Ariz, / singled, 34 $14,645^{\prime}$ N, / 365,166' E, 2830 m, [w, p] // 24.VI.2016, leg. M. Boustani, / A. Kotán, P. Nemes, T. / Németh, M. Rehayem / \& W. Yammine (No. 19) [w, p] // HOLOTYPUS, / Labidostomis / bcharrensis sp. nov., / J. Bezděk des., 2018 [r, p]" (HNHM).

\section{Type locality}

LEBANON: Northern gov., Bcharre env., 4 km E Ariz, 34¹4,645’ N, 365,166’ E.

\section{Description}

Male (holotype, Fig. 1)

Body Length. 5.6 mm (Fig. 1A).

Colouration. Metallic blue with small brownish spot behind each eye, labrum black with thinly pale anterior margin, mandibles black with dark brownish apices. Antennae: antennomeres I-IV yellow, I with largely darkened dorsal side, II-IV with infuscate dorsal side, V black with yellow base, VI-XI black. Pronotum and scutellum metallic blue. Each elytron with large blackish spot covering most of the disc and widely connected with humeral spot, all margins narrowly yellow. Ventral side of body and legs black with slight metallic sheen.

HeAd AND mandiBles. Enlarged (Fig. 1B). Labrum covered with fine microsculpture, anterior margin almost straight with small notch in middle, several pale setae on anterior margin, several additional setae along anterior margin near medial notch. Clypeus laterally with small triangular processes, with divergent apices. Anterior clypeal margin between processes distinctly widely rounded. Clypeal surface almost impunctate and glabrous except several setigerous pores on base of each lateral process bearing long pale seta. Genae large, subtriangular, with large punctures and microsculpture. Frons wide, glabrous, slightly uneven but without any median impression, 4.6 times as wide as transverse diameter of eye, covered with a mixture of large and small punctures. Vertex moderately convex, around eyes with a thin furrow, in middle with an indistinct longitudinal impressed line, surface lustrous, covered with small sparse punctures, glabrous. Mandibles relatively short and robust, dorsal keels sharp and moderately elevated, lateral side distinctly rounded, surface of inner slopes concave, lustrous and impunctate. Lateral side of left mandible subtriangular with slightly rounded upper margin, surface lustrous, covered with small sparse punctures. Antennae short, 0.32 times as long as body, length ratios of antennomeres I-XI equal to 14-6-7-8-9-6-5-5-5-5-9, antennomere I club-shaped, distinctly flattened; II subglobular, III and IV elongate, subparallel, antennae serrated from antennomere V, apex of antennomere XI bidentate.

Pronotum. Pronotum lustrous, glabrous, transverse, 1.70 times as wide as long, covered with small punctures, punctation more intensive along anterior and posterior margins. Anterior margin straight, lateral margins slightly rounded, posterior margin slightly rounded and moderately thickened in scutellar area. Lateral and posterior margins narrowly bordered, anterior margin bordered only in lateral thirds, border in middle part form shallow rounded impression along the margin. Posterior angles nearly rectangular, distinctly elevated upon elytral level. All angles with setigerous pore with long pale seta. Scutellum subtriangular with widely rounded tip, lustrous, glabrous, in basal half covered with small punctures, apical half almost smooth, scutellar apex not elevated upon elytral level. 
ELYTRA. Elytra semicylindrical, parallel, 0.57 as long as body, 1.45 times as long as wide, glabrous, semiopaque, covered with dense confused small punctures and with microsculpture, elytral apices almost impunctate. Basal margin with border disappearing near scutellum. Epipleura glabrous, impunctate, wide in humeral area, suddenly disappearing in basal $1 / 5$ of elytral length. Lateral margin of elytra concave in lateral view.

Legs. Protarsi and protibiae prolonged. Protarsi: protarsomere I elongate, almost parallel, narrowed in basal fifth, subparallel in apical half, 2.44 times as long as wide, protarsomere II subpentagonal, basal third narrowed, apical two thirds parallel, 1.45 times as long as broad, length ratios of protarsomeres I-IV equal to 22-16-14-17. Protarsomeres II and III distinctly wider than I. Length ratios of protarsomeres I-IV equal to 19-10-9-16. Claws narrow, simple, with angulate base.

AedeAgus. Aedeagus small (Fig. 1D), with apical part triangular with almost straight margins and obtuse tip. Dorsal median impression of shield-like shape, without median keel. Apex of aedeagus with inward triangular crooked folds and with small cavity between folds. Operculum transversely semicircular with basal margin slightly rounded. Non-everted anterior sclerite visible as thin process. In lateral view, ventral side distinctly vaulted.

\section{Female}

Unknown.

\section{Distribution}

Lebanon.

Labidostomis damavandensis Rapilly, 1984

Fig. 2

Labidostomis damavandensis Rapilly, 1984: 216 (original description).

\section{Differential diagnosis}

Labidostomis damavandensis is characterised by two spots on each elytron, one small on the humeral callus and one large in the outer part of the posterior half. In Iran and adjacent countries it can be compared only with L. elegans. The two species can be distinguished by the structure of the aedeagus, the structure of the male mandibles (dorsal keel obtuse and placed medially, lateral margins almost straight in L. elegans, dorsal keel sharp and placed along outer margins, lateral margins rounded in L. damavandensis), the structure of the spermatheca and the elytral colouration (each elytron with a large metallic spot placed medially, suture narrowly yellow in L. elegans, large spot placed in outer part of posterior elytral half in Labidostomis damavandensis) (compare Figs 2B, D and G with photographs and drawings of L. elegans in Bezděk 2018).

\section{Material examined}

Holotype

IRAN: 1 đ̆, Fig. 2A, "IRAN Damavand (versant / sud), 3500 m., 15.VII.68 / P. MORVAN [w, h] // HOLOTYPE [r, p] // Museum Paris [p] / Coll. Générale [w, h] // Labidostomis dama- / vandensis Rapilly [h] / M. Rapilly dét. 19 [p] 82 [w, h]" (MNHN).

\section{Other material examined}

IRAN: 1 +, Isfahan prov., Khunsar env., 2550 m a.s.1., 3 Jun. 2000, M. Kalabza leg. (NMPC). 


\section{Type locality}

IRAN: "Iran, Damavand (versant sud)" [southern slope of Damavand Mt., Mazandaran prov.].

\section{Description of female}

Body Length. $6.9 \mathrm{~mm}$.

Colouration. Head, pronotum and scutellum dark metallic blue, labrum black with brownish anterior margin, mandibles black with base and apices brownish (Fig. 2E). Antennae: antennomeres I-IV orange,
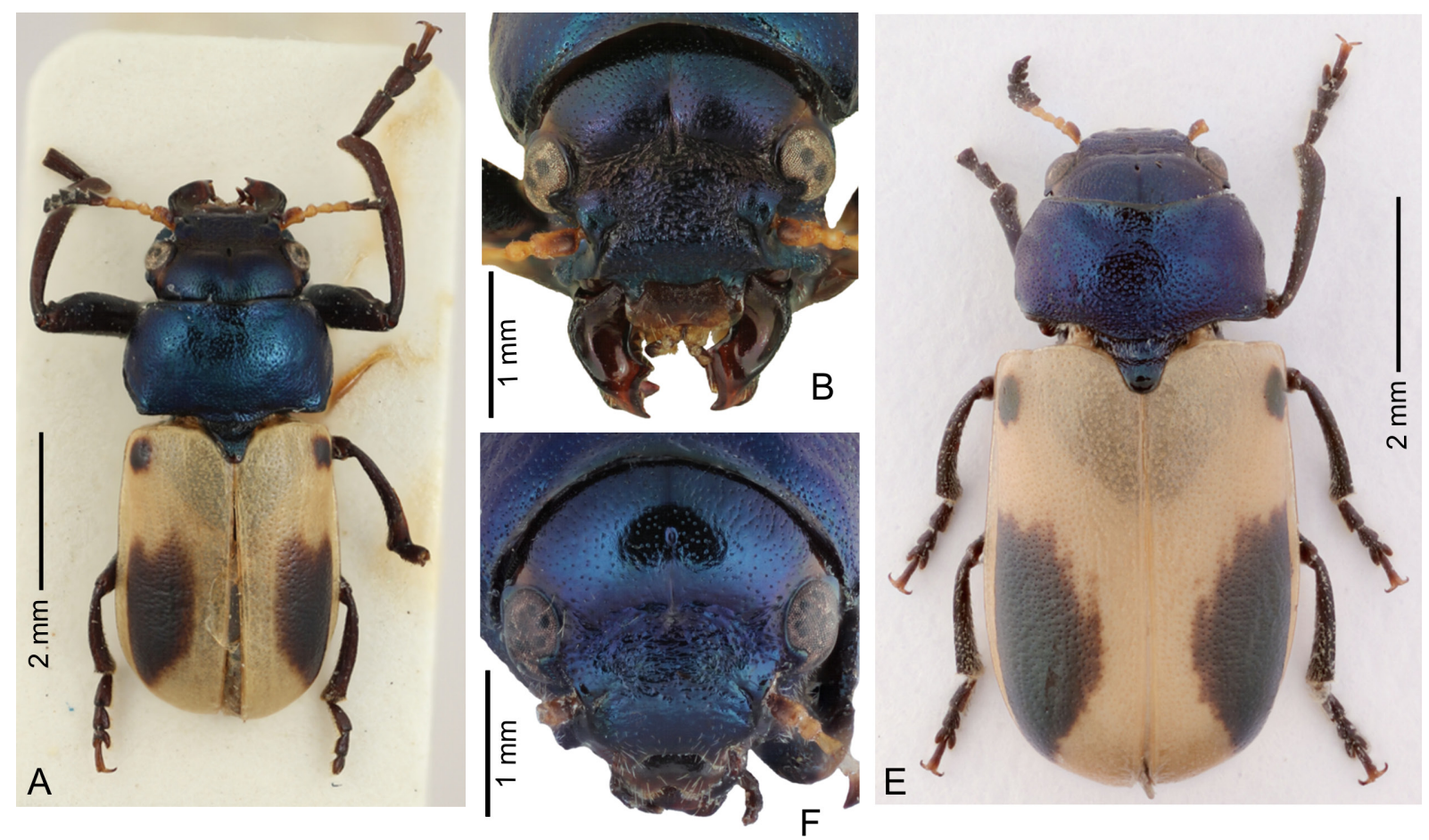

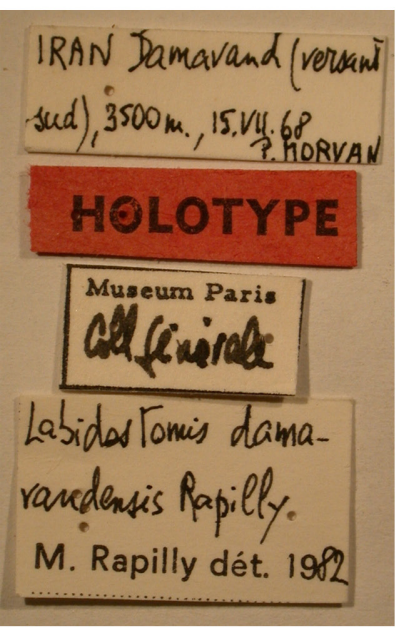

C
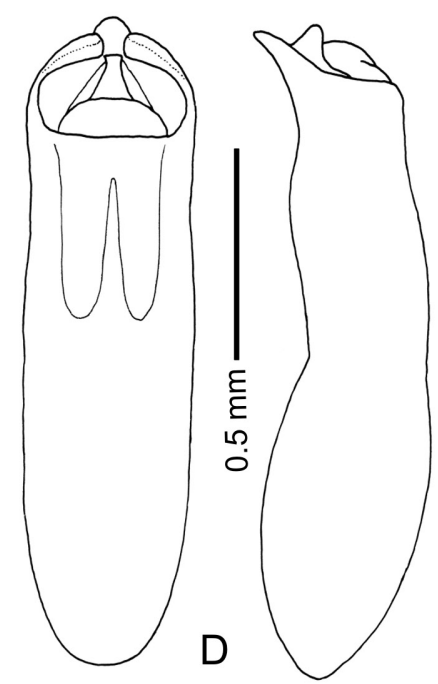
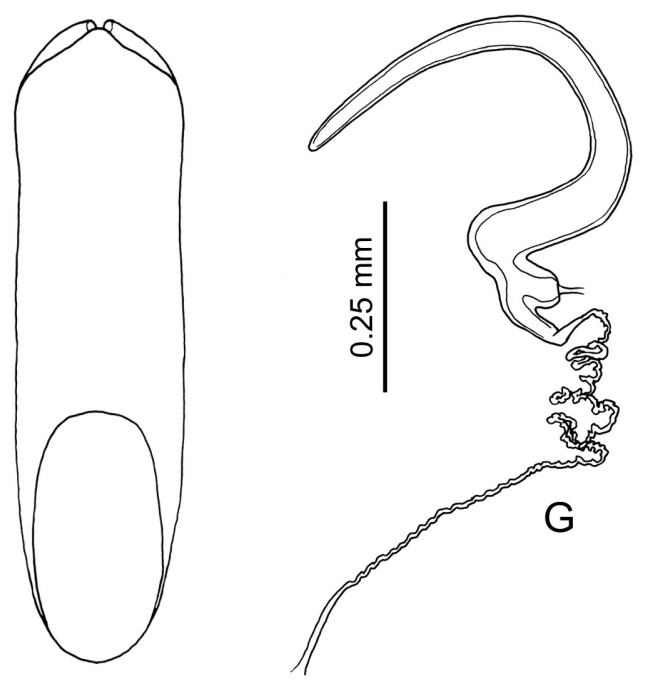

Fig. 2. Labidostomis damavandensis Rapilly, 1984. A-D. Holotype, đ̊, $6.5 \mathrm{~mm}$ (MNHN). A. Dorsal view. B. Head. C. Labels. D. Aedeagus in dorsal, lateral and ventral views. E-G. + , $5.6 \mathrm{~mm}$ (NMPC). E. Dorsal view. F. Head. G. Spermatheca. 
I darkened dorsally, V black with pale base, VI-XI black. Elytra yellow, each elytron with two black spots: small spot on humeral callus, larger elongate spot on outer side of posterior elytral half. Ventral side of body and legs black with slight metallic sheen, claws with paler base.

HEAD. (Fig. 2F). Anterior margin of labrum with wide shallow emargination and several short pale setae, additional longer pale setae placed on surface along anterior margin. Clypeus lustrous with sparse small punctures bearing pale setae, anterior clypeal margin with two small triangular divergent processes, margin between processes straight. Frons 4.33 times as wide as diameter of eye, with transversely elongate impression between eyes, covered with larger punctures mixed with transverse wrinkles and very short indistinct setae. Vertex moderately convex, around eyes with thin furrow, in middle with longitudinal impressed line, in middle of this line with one large elongate puncture, surface glabrous, lustrous, covered with sparse small punctures, basally tending to wrinkles. Antennae short, 0.22 times as long as body, length ratios of antennomeres I-XI equal to 10-5-6-6-6-5-5-5-5-5-10, antennomere I club-shaped, II subglobular, III and IV elongate, subparallel, antennae serrated from antennomere V, XI subapically emarginated from inner and outer sides.

Pronotum. Pronotum lustrous, glabrous, transverse, 1.96 times as wide as long, densely covered with small punctures. Anterior margin widely shallowly concave, lateral margins rounded, posterior margin nearly straight and moderately thickened in scutellar area. Lateral and posterior margins narrowly bordered, anterior margin bordered only in lateral thirds, border in middle part forming shallow rounded impression along the margin. Posterior angles nearly rectangular, distinctly elevated upon elytral level. Scutellum subtriangular with widely rounded tip, in basal half covered with small punctures and short setae, and with slightly elevated impunctate median line, apical half glabrous, with disappearing punctation towards apex, impressed along apex, scutellar apex not elevated upon elytral level.

ElYTRA. Elytra semicylindrical, parallel, 0.69 as long as body, 1.55 times as long as wide, glabrous, semiopaque, covered with dense confused small punctures mixed with very small punctures and with microsculpture, elytral apices almost impunctate. Basal margin with distinctly elevated sharp border disappearing near scutellum. Epipleura glabrous, impunctate, wide in humeral area, suddenly disappearing in basal $1 / 5$ of elytral length. Lateral margin of elytra concave in lateral view.

LENGTH RATIOS. Length ratios of protarsomeres I-IV equal to 8-5-5-8, of metatarsomeres I-IV equal to 7-4-4-8. Claws narrow, simple, with angulate base.

SPERMATHECA. Vasculum extremely long and thin, base somewhat wider, gradually narrowed to apex. Bulbus as wide as base of vasculum, divided into two parts. Ductus spermathecae ca 2.5 times as long as vasculum, with many small loops, only distal part without loops, proximal part tangled (Fig. $2 \mathrm{G}$ ).

\section{Distribution}

Iran.

Labidostomis rufa (Walt1, 1838)

Fig. 3

Clythra rufa Walt1, 1838: 472 (original description).

Clythra (Labidostomis) rufa Lacordaire, 1848: 43 (original description), syn. nov.

\section{Material examined}

\section{Holotype}

Not examined. Not traced in NMHW where large part of Waltl's collection is deposited. 


\section{Syntype}

MACEDONIA: 1 đ, syntype of Clythra rufa Lacordaire, 1848, "Macedonien / Frivaldsky, 12.8. [w, h] // Type [r, p] // not type ! [h] / L. N. Medvedev det. 19 [p] 69 [w, h] // Hist.-Coll. (Coleoptera) / Nr. 23068 / Labidostomis rufa Lac. x / Macedon., Frivaldsky / zool. Mus. Berlin [w, p] // SYNTYPE / Labidostomis / rufa Lacordaire, 1848 / labelled by MFNB 2017 [r, p]" (ZMHB).

\section{Other material examined}

ISRAEL: $8 \hat{\jmath} \hat{\jmath}, 4$ 우, Haifa, without date of collecting, Reitter leg. (NMPC).

\section{Type localities}

Clythra rufa Waltl, 1838

TURKEY: "Türkey" [by the title].

Clythra rufa Lacordaire, 1848

TURKEY, GREECE: "environs de Constantinople, des provinces nord de la Grèce".

\section{Distribution}

Bulgaria, Greece, Macedonia, Turkey (Regalin \& Medvedev 2010b), Iran (Ghahari \& Jedryczkowski 2012). New species for Israel.

\section{Comments}

Labidostomis rufa was described by Waltl (1838). Ten years later, Lacordaire (1848) published the description of Clythra (Labidostomis) rufa Lacordaire, 1848 attributed to Frivaldsky based on males only. At the end of the description, Lacordaire mentioned that Frivaldsky's description was unknown to him and, moreover, Labidostomis rufa Waltl, 1838 is mentioned nowhere in the text. Despite the fact that all subsequent authors have referred Lacordaire's description to Waltl's Labidostomis rufa, I am convinced that Lacordaire's Clythra (Labidostomis) rufa must be treated as a validly described
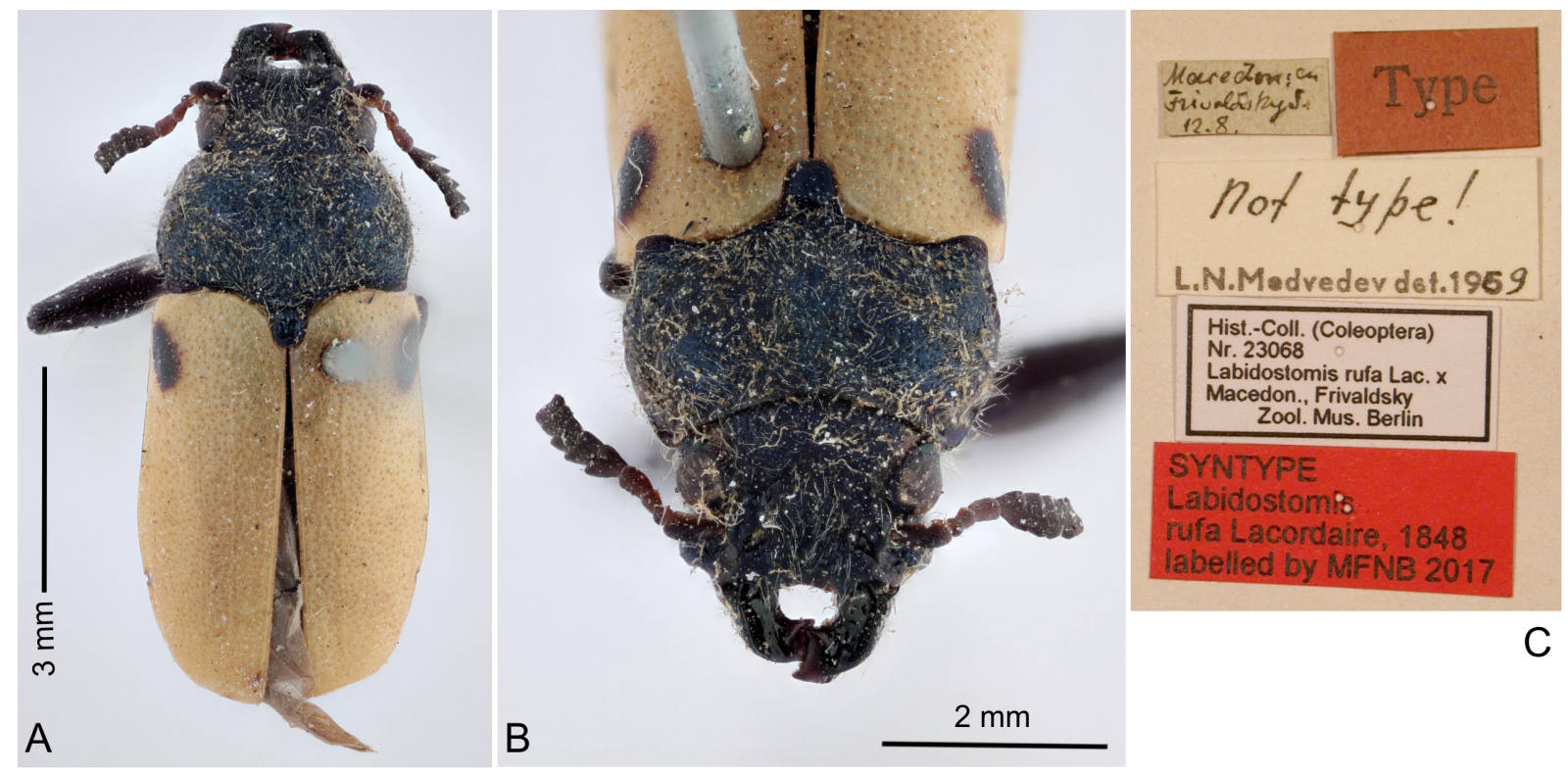

Fig. 3. Labidostomis rufa (Waltl, 1838), syntype of Clythra (Labidostomis) rufa Lacordaire, 1848, §̂, $9.0 \mathrm{~mm}$ (ZMHB). A. Dorsal view. B. Frontal view. C. Labels. 
taxon. Based on one male syntype (Fig. 3A-C, deposited in ZMHB), I synonymize Labidostomis rufa Lacordaire, 1848 with Labidostomis rufa (Waltl, 1838).

Tituboea decemguttata Walker, 1871, nomen dubium

Tituboea decemguttata Walker, 1871: 18 (original description).

\section{Material examined}

Type material not examined.

\section{Type locality}

EGYPT: Cairo.

\section{Comments}

Tituboea decemguttata Walker, 1871 was described from Cairo, Egypt (Walker 1871). Unfortunately, the collection of John Keast Lord, which included Walker's type material from his 1871 paper, was destroyed (Horn et al. 1990). As mentioned by Bezděk \& Batelka (2011), no specimens were found in the institutions housing parts of Walker's collection: The Natural History Museum (London), University Museum of Natural History (Oxford), and Museum Victoria (Melbourne). The original description of Tituboea decemguttata is uninformative, predominantly based on colour characters, which are highly variable in the species of Tituboea.

Over the last 40 years, Tituboea decemguttata was published from various countries of the Near East and the Arabian Peninsula (Medvedev 1979, 1996; Katbeh-Bader \& Medvedev 2000; Lopatin et al. 2003). Regalin \& Medvedev (2010b) summarised the distribution as follows: Egypt, Israel, Jordan, Oman, Saudi Arabia and Yemen. However, almost all the specimens identified as Tituboea decemguttata which I have examined in various collections proved to be Tituboea lacordairei (Pic, 1929).

Due to the loss of the type material and the uninformative description, I cannot resolve the species' identity with certainty. It cannot be excluded that the original type specimen(s) really were conspecific with Tituboea lacordairei because the westernmost known locality of Tituboea lacordairei is in the Sinai Peninsula (Bezděk \& Regalin 2015), relatively near to Cairo. However, Tituboea decemguttata may also be conspecific with another species of Tituboea, for example Tituboea arabica (Olivier, 1808) or Tituboea olivieri (Lacordaire, 1848). Unfortunately I have seen no specimens from Egypt with a colouration as described in the original description, which could be used for neotype designation. At present, the best course of action seems to me to consider Tituboea decemguttata as a nomen dubium.

Tituboea friedmani Bezděk sp. nov. urn:1sid:zoobank.org:act:D338C720-288A-42B6-8CF2-625C02BBB640

Figs 4, 5A-B

\section{Differential diagnosis}

Tituboea friedmani sp. nov. is similar to Tituboea chobauti (Pic, 1896) (Algeria, Egypt, Jordan, Morocco) and Tituboea atriceps Pic, 1924 (Egypt, Israel, Iraq) (Fig. 4G-H). All three species differ in the colouration of the legs: femora black and tibiae pale in Tituboea chobauti, femora and tibiae pale in Tituboea atriceps, femora and tibiae black (or basal half of tibiae pale) in Tituboea friedmani sp. nov. The pronotum of Tituboea chobauti is covered with very dense small punctures while the pronotal punctation in Tituboea friedmani sp. nov. and Tituboea atriceps is sparser and irregular. All the species can also be distinguish by the structure of the aedeagus. In lateral view, the ventral margin 
of the aedeagus is almost straight and the apex turned dorsally in Tituboea friedmani sp. nov. while the ventral margin is distinctly rounded and the apex not turned in Tituboea chobauti and Tituboea atriceps (Fig. 5A, C, E). The spermatheca of all three species of similar shape (Fig. 5B, D, F).
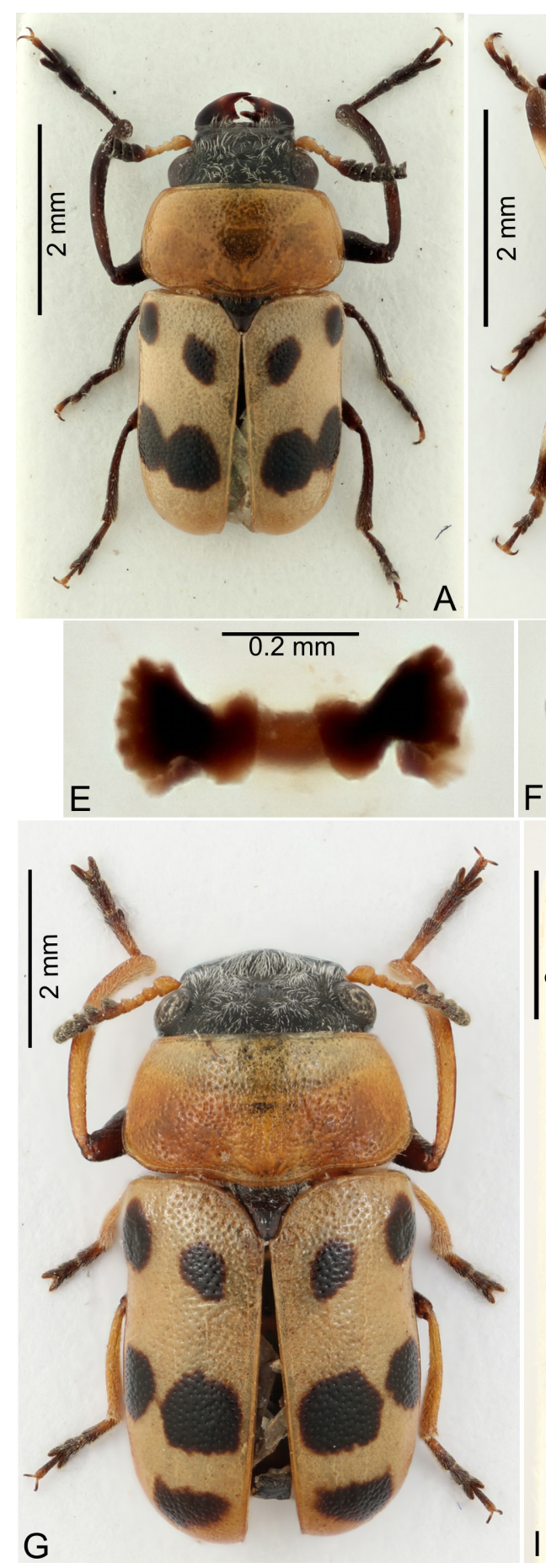
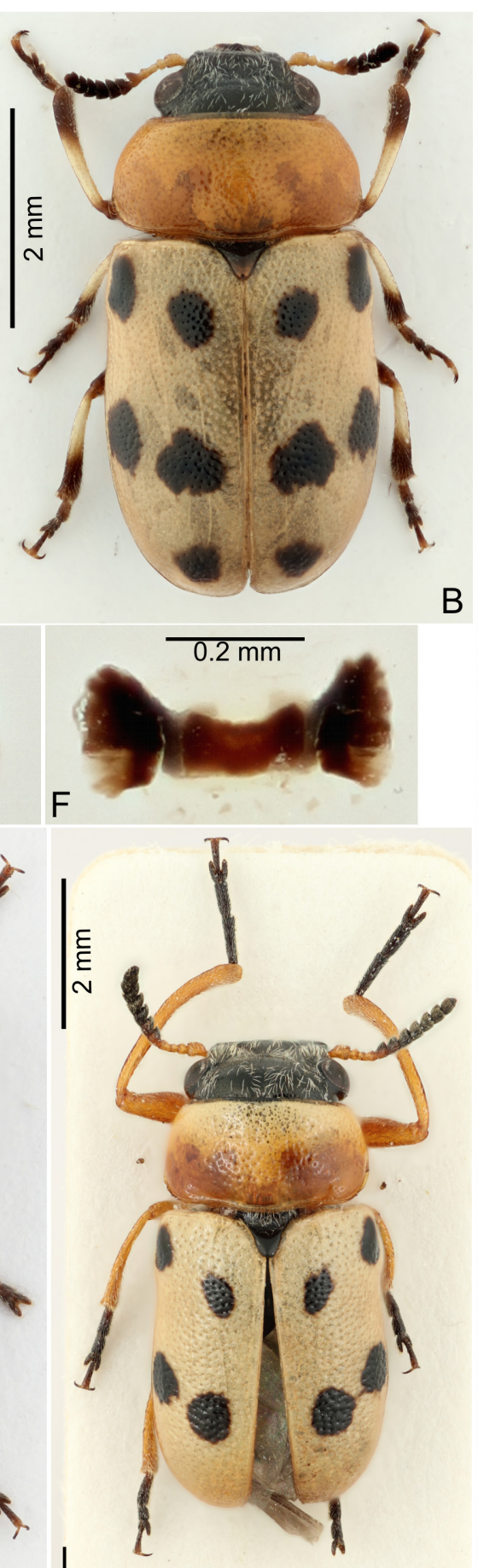
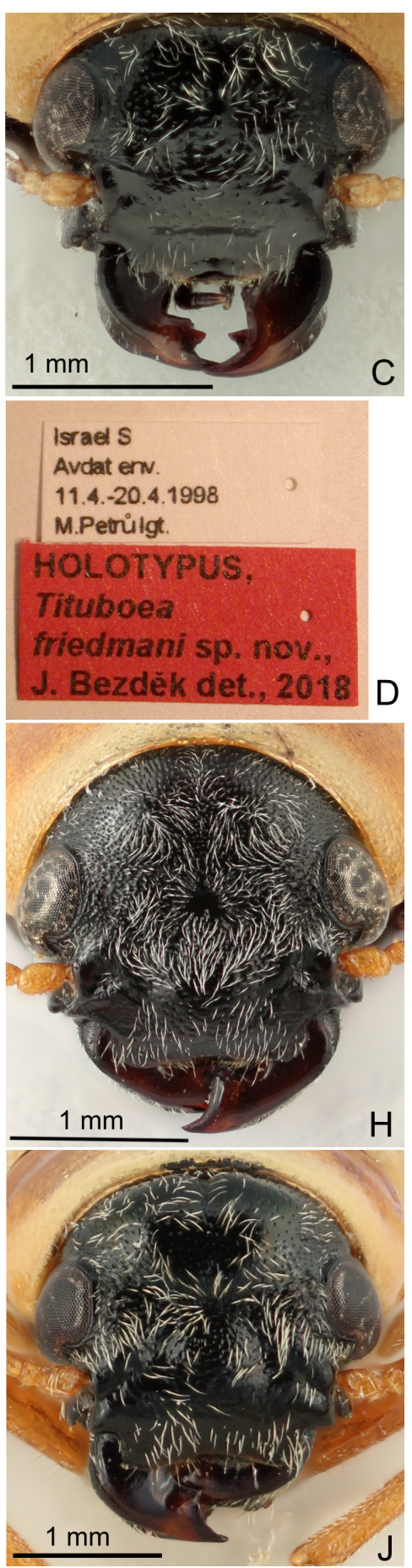

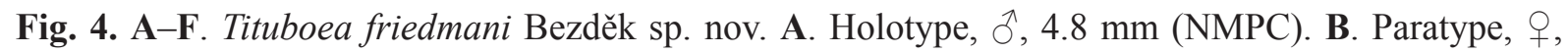
$4.6 \mathrm{~mm}$ (TAU). C. Male head. D. Labels of holotype. E. Kotpresse, ventral sclerites. F. Kotpresse, dorsal sclerites. G-H. T. chobauti (Pic, 1896). G. Ô, $6.1 \mathrm{~mm}$. H. Head. I-J. T. atriceps Pic, 1924. I. Ô, $6.0 \mathrm{~mm}$. J. Head. 


\section{Etymology}

Dedicated to Ariel-Leib-Leonid Friedman (TAU), who collected most of the specimens of this new species.

\section{Material examined}

\section{Holotype}

ISRAEL: 1 §ૈ, “Israel S / Avdat env. / 11.4.-20.4.1998 / M. Petrů lgt. [w, p]” (NMPC).

\section{Paratypes}

ISRAEL: 1 ô, “178157.ISRAEL: / ZometRotem, 6 km S / 410m, 1.iv.2014 / L. FRIEDMAN / on Calligonum / comosum [w, p]" (TAU); 1 ㄱ, 2 우, "ISRAEL: / Ashalim / 5.iv.1999 / V. CHIKATUNOV [w, p] // On Polygonum sp. / 5.iv.1999 / V. CHIKATUNOV [w, p] // Antipa / decemguttata / Walk. [h] / det. I. Lopatin, 19. [p] 99 [w, h]" (TAU); 1 क, "Jericho [h] / PALESTINE [p] / $23.1 \mathrm{i}[\mathrm{h}] 19$ [p] 41 [h] / leg. Bytinski-Salz [w, p] // Antipa / Chobauti Pic [h] / det. F. Stöcklein 195 [p] 2 [w, h] // Antipa / decemguttata / Walk. [h] / det. I. Lopatin, 19. [p] 99 [w, h]" (TAU). The type specimens are provided with one printed red label: "HOLOTYPUS, [or PARATYPUS, resp.] / Tituboea / friedmani sp. nov., / J. Bezděk det. 2018".
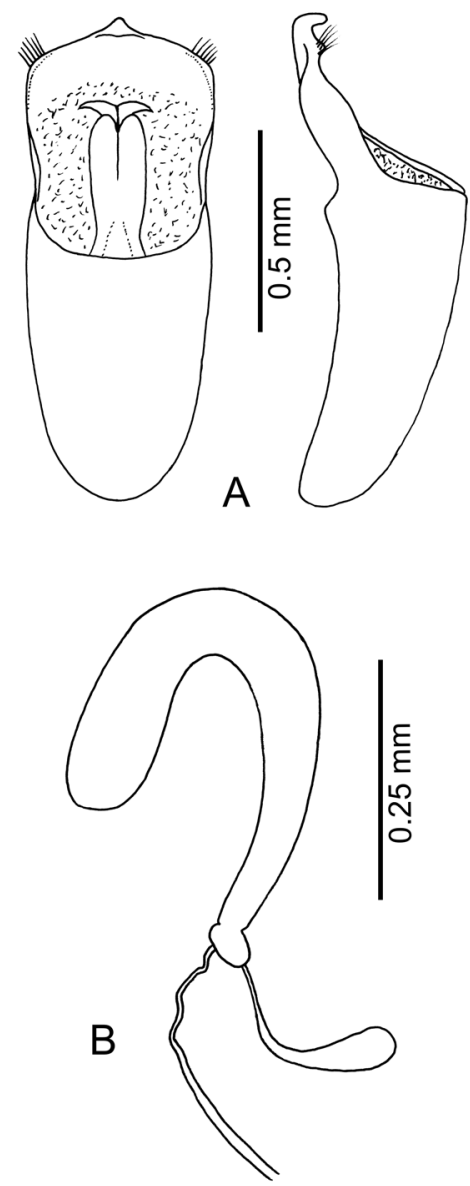
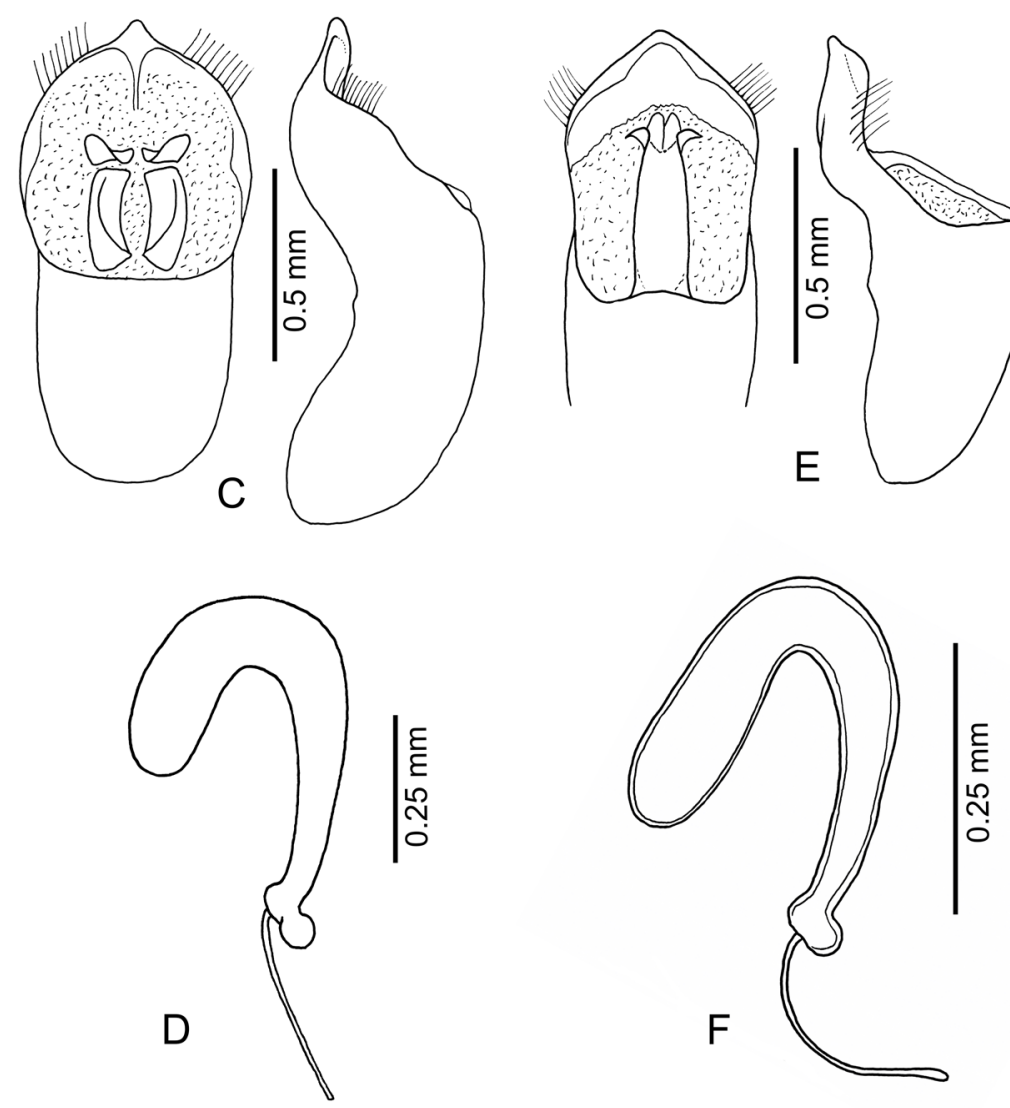

Fig. 5. A-B. Tituboea friedmani Bezděk sp. nov. A. Aedeagus in dorsal and lateral views. B. Spermatheca. C-D. T. chobauti (Pic, 1896). C. Aedeagus in dorsal and lateral views. D. Spermatheca. E-F. T. atriceps Pic, 1924. E. Aedeagus in dorsal and lateral views. F. Spermatheca. 


\section{Type locality}

ISRAEL: Avdat env.

\section{Description}

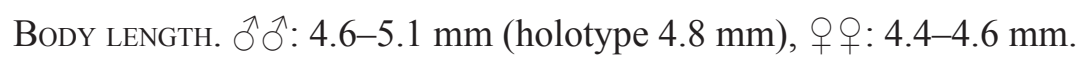

Male (holotype, Fig. 4)

Colouration. Head black, apical parts of mandibles reddish, antennomeres I-IV yellow, V brownish basally. Pronotum orange. Scutellum black. Elytra yellow, each elytron with four black spots $(2,2)$, posterior pair connected. Underside black. Legs black, knees brownish (Fig. 4A).

HEAD. Mandibles distinctly enlarged, dorsal side flat, almost even, lateral sides of both mandibles moderately concave (Fig. 4C). Labrum almost invisible, with a straight anterior margin. Clypeus with bisinuate anterior margin, surface transversely impressed, very finely punctate, with longer pale setae cumulated laterally. Eyes small. Frons very wide, 4.88 times as wide as diameter of eye, surface uneven, densely covered with small punctures and short pale setae. Frons not separated from vertex. Vertex lustrous, covered with small punctures (finer than on frons) and short pale setae, with indistinct median line. Antennae short, 0.28 times as long as body, antennomere I club-shaped, II small, subglobular, III very small, IV triangular with produced apical angle, antennae shortly serrated from antennomere V, antennomeres $\mathrm{V}-\mathrm{X}$ wider than long.

Pronotum. Pronotum glabrous, lustrous, strongly transverse, 1.80 times as wide as long, widest at basal half, moderately convex, irregularly covered with small punctures, punctures larger on disc, finer in lateral parts. Anterior margin straight, lateral margins rounded, posterior margin nearly straight but shallowly bisinuate in scutellar area. Anterior angles obtusangulate, posterior angles widely rounded. Lateral and posterior margins thinly bordered, anterior margin bordered only at lateral parts, in middle border almost invisible. Posterior angles not elevated above elytral base.

Scutellum. Scutellum subtriangular with rounded tip, in basal half punctate and covered with setae, towards apex becoming impunctate and glabrous, scutellar apex slightly elevated upon elytral level.

ElYTRA. Elytra short, subcylindrical, 0.55 times as long as body, 1.15 times as long as wide at humeral part, glabrous, lustrous, densely covered with small confused punctures, disappearing at elytral apices. Basal margin with complete thin border forming a narrow elevated keel, sharp in outer half, somewhat swollen in inner half. Epipleura impunctate, glabrous, wide in anterior fifth, suddenly narrowed and disappearing in anterior $1 / 5$ of elytral length. Lateral margin of elytra widely concave in lateral view.

LeGs. Protibiae moderately prolonged. Protarsomere I very thin, 5.0 as long as broad, parallel, protarsomere II wider as I, length ratios of protarsomeres I-IV equal to 10-7-5-7. Metatarsi short and thin, length ratios of metatarsomeres I-IV equal to 7-4-3-6. Claws simple.

Male genitalia. Aedeagus 2.5 times as long as wide. In dorsal view, apex moderately rounded with pointed tip. In lateral view, the ventral margin of aedeagus is almost straight and apex forming small hook directed upwards (Fig. 5A).

\section{Female}

Head, mandibles and anterior legs not enlarged. Protarsomeres extremely short, length ratios of protarsomeres I-IV equal to 3-2-2-4. Spermatheca: cornu U-shaped, apical half wider and somewhat shorter than basal one, basal half gradually narrowed towards very small nodulus, proximal spermathecal duct ca 0.8 times as long as cornu (Fig. 5B). Kotpresse as in Fig. 4E-F. 


\section{Variability}

Black spots on elytra slightly variable in size, posterior pair can be either separated or partially connected. One female paratype (Fig. 4B) with additional small black spot subapically on each elytron. Two specimens with pale basal halves of each tibiae.

\section{Bionomy}

Based on the label data, the specimens were collected on Calligonum comosum L'Hér. and on a species of Polygonum L. (Polygonaceae Juss.).

\section{Distribution}

Israel.

Tituboea harteni Bezděk sp. nov.

urn:lsid:zoobank.org:act:714861E4-A62E-40A6-8CF3-1DFF75897B95

Figs 6, 7A

\section{Differential diagnosis}

Tituboea harteni sp. nov. resembles three species distributed in the southern Arabian Peninsula: Tituboea lacordairei (Pic, 1929), Tituboea pindai Bezděk, 2011 and Tituboea ogloblini (Medvedev, 1962). Tituboea harteni sp. nov. can be easily distinguished by the shorter male protarsi and protarsomere I 3.2 times as long as wide (protarsi more prolonged and protarsomere I ca five times as long as wide in other three species) and in the structure of the aedeagus (tricuspidate in Tituboea harteni sp. nov., triangular in the other three species) (Fig. 7).

\section{Etymology}

Dedicated to Antonius van Harten, the collector of the new species.
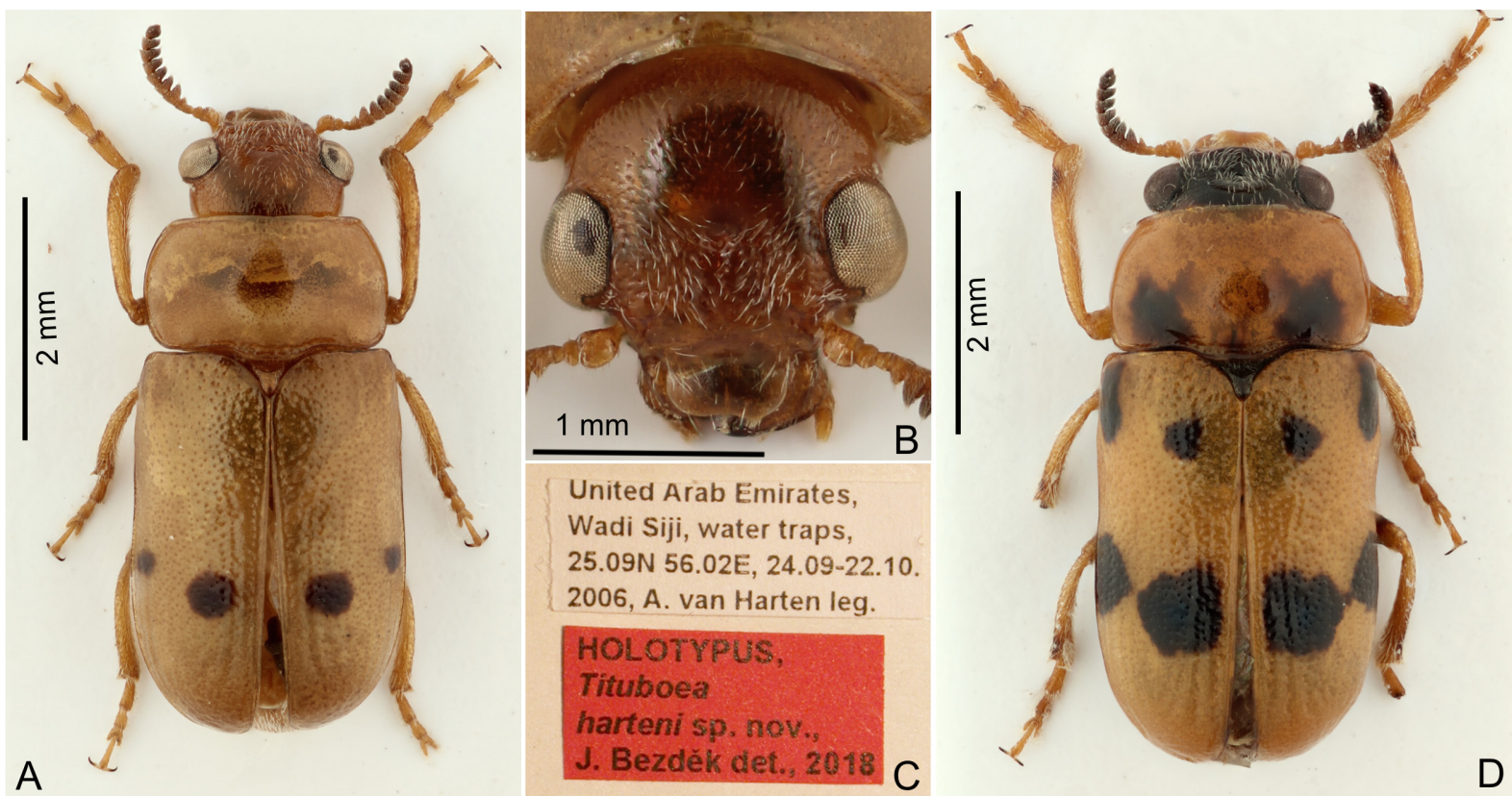

Fig. 6. Tituboea harteni Bezděk sp. nov. A-C. Holotype, đ̂, 5.2 mm (NMPC). A. Dorsal view. B. Head. C. Labels. D. Paratype, ô, $5.3 \mathrm{~mm}$, dorsal view (JBCB). 


\section{Material examined}

\section{Holotype}

UNITED ARAB EMIRATES: 1 ô, "United Arab Emirates, / Wadi Siji, water traps, / 25.09N 56.02E, 24.09-22.10. / 2006, A. van Harten leg. [w, p]" (NMPC). The type specimens are provided with one printed red label: "HOLOTYPUS, [or PARATYPUS, resp.] / Tituboea / harteni sp. nov., / J. Bezděk det. $2018 "$.

\section{Paratypes}

1 o, "United Arab Emirates, / Wadi Bih dam, / 19.ii.-30.iv.2008, light trap, / A. van Harten leg. [w, p]" (JBCB); 1 §, "N Oman, Al Batinah / North Gov., W of / Falaj Bani Rabiah / lgt. J. Pelikán 1.4.2018 [w, p] // 2350'13.101"N / 57 $4^{\prime} 55.710^{\prime \prime E} 101 \mathrm{~m} /$ kamenitá poušt' [stony desert] / noč. lov na UV světlo [night collecting at UV light] [w, p] // COLLECTION / JAN PELIKÁN / Hradec Králové / Czech republic [w, p]" (JPCH).

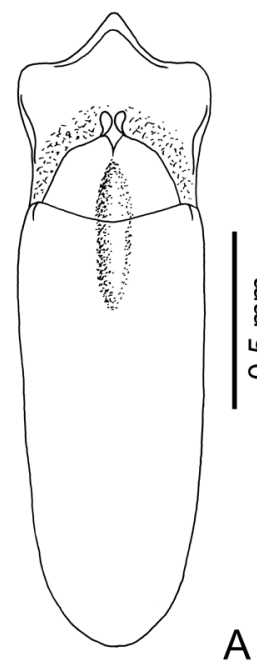

A
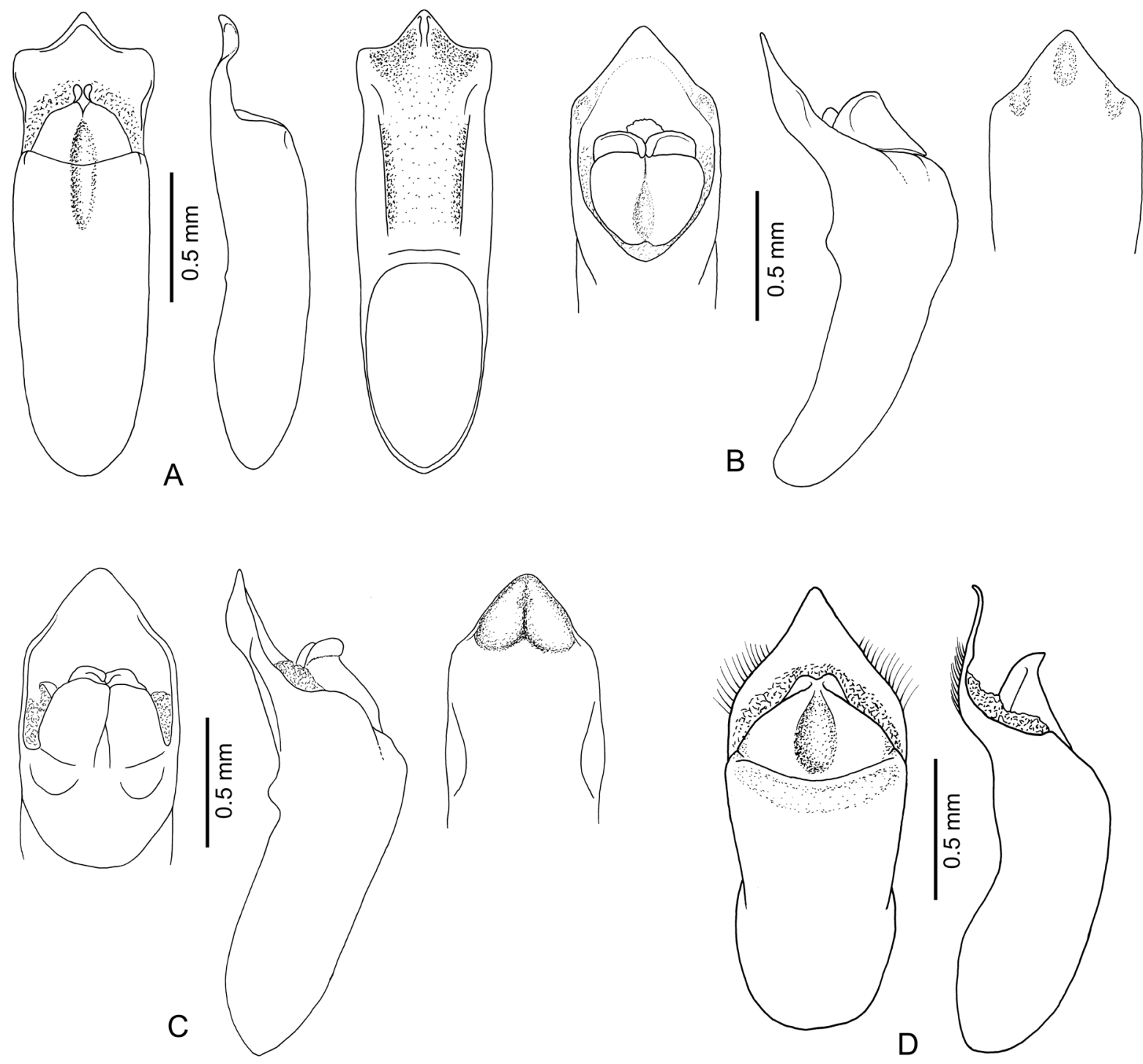

Fig. 7. Aedeagus in dorsal, lateral and ventral views. A. Tituboea harteni Bezděk sp. nov. B. T. lacordairei (Pic, 1929). C. T. ogloblini (Medvedev, 1962). D. T. pindai Bezděk, 2011. 


\section{Type locality \\ UNITED ARAB EMIRATES: Wadi Siji.}

\section{Description}

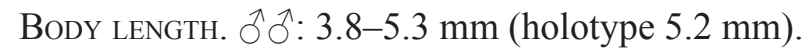

Male (holotype, Fig. 6)

Colouration. Body completely orange, except gradually darkened antennomeres VI-XI, black apices of mandibles, claws and two small black spots on each elytron behind middle (outer spot smaller and placed slightly more anteriorly).

Head And mandibles. Not enlarged (Fig. 6B). Mandibles small. Labrum semiopaque, transverse, with anterior angles widely rounded and anterior margin shallowly emarginated, surface with four long setae along anterior margin. Clypeus lustrous, almost impunctate, with longer pale setae cumulated laterally, anterior margin almost straight. Eyes moderately large. Frons wide, 3.18 times as wide as diameter of eye, surface uneven, densely covered with larger punctures and short pale setae, posteriorly in middle distinctly impressed. Frons indistinctly separated from vertex. Vertex lustrous, covered with small punctures and short pale setae, with indistinct median line. Antennae short, 0.21 times as long as body, antennomere I club-shaped, II small, subglobular, III very small, antennae serrated from antennomere IV, antennomeres $\mathrm{V}-\mathrm{X}$ wider than long.

Pronotum. Pronotum glabrous, lustrous, strongly transverse, 1.86 times as wide as long, widest in middle, moderately convex, covered with irregular mixture of fine and very fine punctures. Anterior margin straight, lateral margins rounded, posterior margin nearly straight but moderately thickened in scutellar area. Anterior angles obtusangulate, posterior angles widely rounded. Lateral and posterior margins thinly bordered, anterior margin bordered only at lateral parts, in middle border is almost invisible. Posterior angles slightly elevated above elytral base.

Scutellum. Scutellum subtriangular with rounded tip, in basal half punctate and covered with setae, towards apex becoming impunctate and glabrous, scutellar apex elevated upon elytral level.

ELYTRA. Elytra subcylindrical, 0.60 times as long as body, 1.41 times as long as wide at humeral part, glabrous, lustrous, densely covered with small confused punctures, in posterior half with indistinct traces of regular punctation. Basal margin with complete thin border forming narrow elevated keel. Epipleura impunctate, glabrous, wide in anterior quarter, suddenly narrowed and disappearing in anterior $1 / 4$ of elytral length. Lateral margin of elytra widely concave in lateral view.

LEGS. Protibiae moderately prolonged. Lateral margins of all protarsomeres covered with long setae. Protarsomere I moderately prolonged, narrow, 3.2 as long as broad, parallel except convergent basal part, protarsomere II elongate subtriangular, as wide as I, length ratios of protarsomeres I-IV equal to 8-6-5-7. Metatarsi short and slender, length ratios of metatarsomeres I-IV equal to 5-4-3-6. Claws simple.

Genitalia. Aedeagus three time as long as wide, apical part tricuspidate, middle part triangular, sharp, lateral angles widely rounded. In ventral view, apex with short keel and two large impressions, middle part with two lateral sharp keels (Fig. 7A).

VARIABILITY. Paratype from UAE (Fig. 6D) with broad black band between eyes, pronotum with two black spots near basal margin, scutellum black, each elytron with four black spots (two, two), underside black, anterior legs with black coxae, middle and hind legs with black coxae and basal $2 / 3$ of femora, 
outer margin of all tibiae near apex infuscate. The paratype from Oman is a very small male with a comparatively smaller and less developed aedeagus in comparison with the two males from UAE.

\section{Female}

Unknown.

\section{Distribution}

United Arab Emirates.

Tituboea olivieri (Lacordaire, 1848)

Fig. 8

Clythra (Tituboea) olivieri Lacordaire, 1848: 159 (original description).

Tituboea femoralis Medvedev, 1962: 335 (original description), syn. nov.
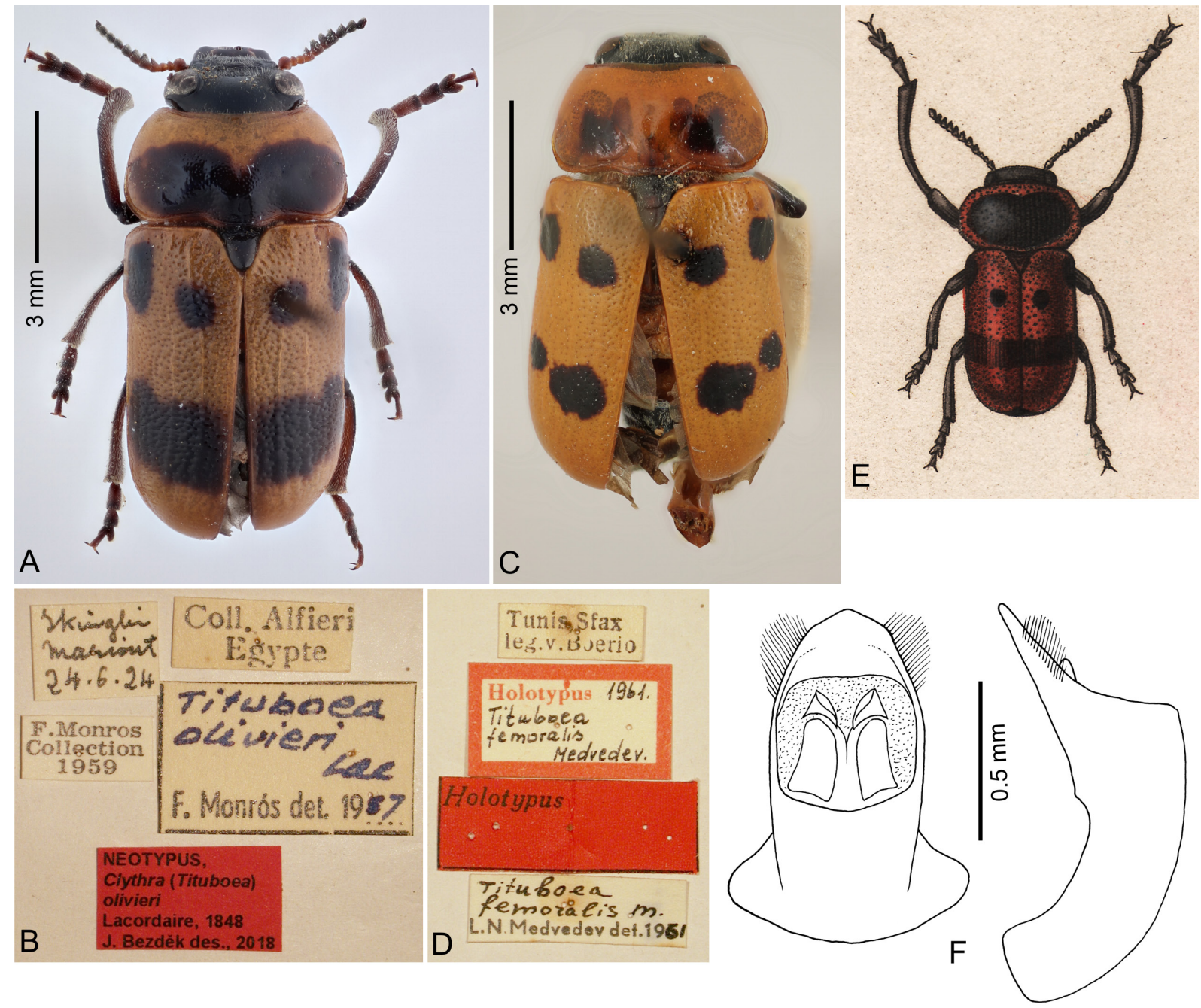

Fig. 8. Tituboea olivieri (Lacordaire, 1848). A-B. Neotype, ô, $9.4 \mathrm{~mm}$ (USNM). A. Dorsal view. B. Labels. C-D. Holotype of T. femoralis Medvedev, 1962 (HNHM). C. Dorsal view. D. Labels. E. Drawing of T. olivieri from Lefèvre (1872). F. Aedeagus in dorsal and lateral views, ठ̂, Tunisia, Gabes (NMPC). 
BEZDĚK J., Clytrini of the Eastern Mediterranean, the Near East and the Arabian Peninsula

\section{Material examined}

\section{Type material}

TUNISIA: $1 \hat{\jmath}$, holotype of Tituboea femoralis, “Tunis, Sfax / leg. V. Boerio [w, p] // Holotypus [red letters, p] 1961. / Tituboea / femoralis / Medvedev. [white label with red borders, h] // Holotypus [r, p] // Tituboea / femoralis m. [h] / L. N. Medvedev det. 19 [p] 61 [w, h]" (HNHM).

EGYPT: 1 ô, neotype of Tituboea olivieri, "Ikinghi / Mariout / 24.6.24 [w, h] // Coll. Alfieri / Egypte [w, p] // F. Monros / Collection / 1959 [w, p] // Tituboea / olivieri / Lac. [h] / F. Monrós det. 19 [p] 57 [w, h] // NEOTYPUS, / Clythra (Tituboea) / olivieri / Lacordaire, 1848 / J. Bezděk des., 2018 [r, p]" (USNM).

\section{Other material}

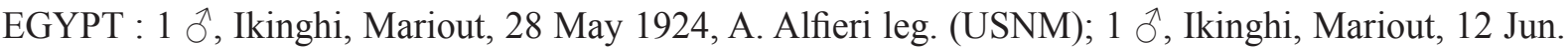
1925, A. Alfieri leg. (USNM).

LIBYA: 1 q, Misurata, 20 Jan. [without year of collecting], Bačovský leg. (JBCB).

TUNISIA: $2 \widehat{\jmath}$, Gabes, without date of collecting, J. Obenberger leg. (NMPC).

\section{Type localities}

Clythra olivieri

EGYPT: "Égypte".

Tituboea femoralis

TUNISIA: Sfax.

\section{Comments}

Lacordaire (1848) described Tituboea olivieri from Egypt based on material received from Chevrolat, but did not specify the number of specimens, only explicitly mentioning the unknown female. Lefèvre (1872) noted only one male in Chevrolat's collection (presumably the holotype) and published a colour drawing of its habitus (Fig. 8E). Unfortunately, the type has not been traced in either the MNHN or $\mathrm{BMNH}$, where Clytrini from Chevrolat's collection are deposited now. I treat the holotype as lost.

Recently, I examined 3 specimens from Egypt deposited in USNM, which exactly match the colouration published in Lefèvre (1872). Surprisingly, these specimens are conspecific with Tituboea femoralis (Fig. 8C) but with the black pattern extended in comparison with the specimens from Tunisia and Libya. I decided to designate one of the males as a neotype (Fig. 8A) to fix the identity of Tituboea olivieri and, subsequently, to propose Tituboea femoralis as a new synonym of Tituboea olivieri.

Tituboea radeki Bezděk sp. nov. urn:1sid:zoobank.org:act:EE1F6A21-B8B8-4D0A-B613-6AA41BFA1E72

Figs 9, 10A-B

\section{Differential diagnosis}

Tituboea radeki sp. nov. is very similar to Tituboea arabica (Olivier, 1808) (Fig. 9G). The males of the two species differ in the shape of the protarsomeres. In Tituboea radeki sp. nov. protarsomere I is 1.65 times as long as wide and only slightly longer than subtriangular protarsomere II, while protarsomere I is 2.25 times as long as wide and 1.3 times longer than parallel protarsomere II in Tituboea arabica. The dorsal opening of the aedeagus of Tituboea arabica is subquadrangular, with a widely triangular apex while the apical part is regularly rounded towards the apex in Tituboea radeki sp. nov. In lateral view, 
the apex of the aedeagus of Tituboea arabica is abruptly bent upwards at an angle of ca $40^{\circ}$, while it is only slightly and gradually bent in Tituboea radeki sp. nov. (Fig. 10A, C). The spermatheca is similar in both species; the proximal spermathecal duct is 0.9 times as long as the cornu in Tituboea radeki sp. nov., but 1.2 times as long in Tituboea arabica (Fig. 10B, D).

\section{Etymology}

Dedicated to the late Radek Červenka, specialist in Scarabaeidae and the collector of the holotype.

\section{Material examined}

\section{Holotype}

OMAN: 1 ڤึ, "OMAN mer., ca 0-50m, / Al Mughsayl env., / 21.-23.x.2005, / R. Červenka leg. [w, p]" (NMPC). The type specimens are provided with one printed red label: "HOLOTYPUS, [or PARATYPUS, resp.] / Tituboea / radeki sp. nov., / J. Bezděk det. 2018".
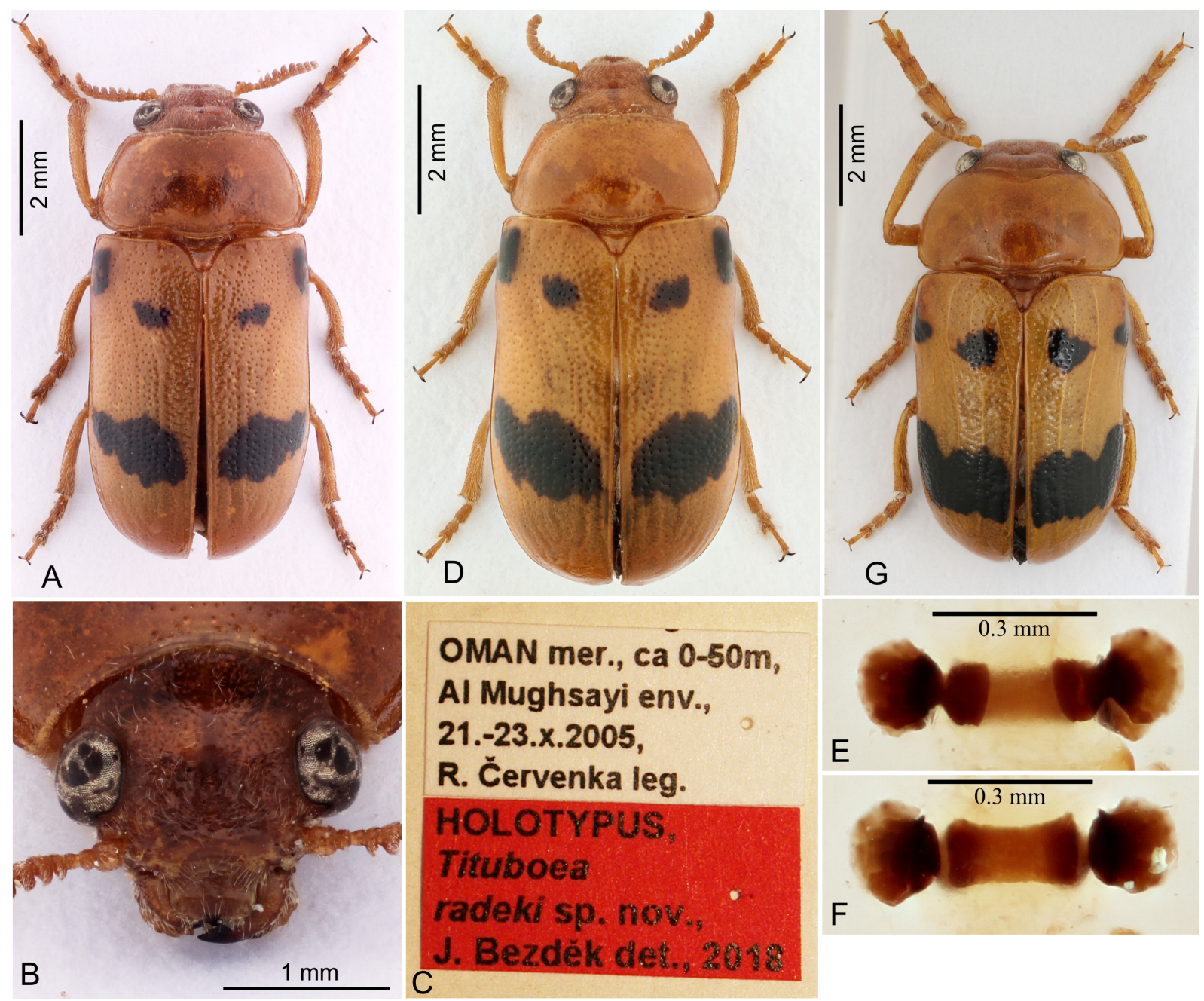

Fig. 9. A-C, E-F. Holotype of Tituboea radeki Bezděk sp. nov., đ̂, $8.1 \mathrm{~mm}$ (NMPC). D. Paratype of Tituboea radeki Bezděk sp. nov., + 7.4 mm (LSCP). A. Dorsal view. B. Head. C. Labels. D. Dorsal view. E. Kotpresse, ventral sclerites. F. Kotpresse, dorsal sclerites. G. T. arabica (Olivier, 1808), ठ̂, $8.0 \mathrm{~mm}(\mathrm{JBCB})$. 


\section{Paratypes}

OMAN: 1 Oे, “Al Mughsayl dint. E / 16 $6^{\circ} 52^{\prime} 53^{\prime \prime N} / 53^{\circ} 43^{\prime} 51^{\prime \prime E ~ / ~ 08 . I I I .2004 ~[w, ~ p] ~ / / ~ O m a n ~ / ~ D h o f a r ~}$ Region / Leg. Dellacasa M. [w, p] // Museo di Storia / Naturale e del / Territorio / Universita di Pisa /

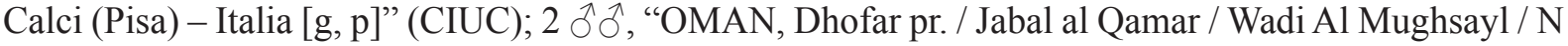
$16^{\circ} 52^{\prime}$ E 5343' / 2-3.10.2013 (10-120 m n. m.) / lgt. P. Kučera [w, p]" (LSCP, JBCB); 1 + , "OMAN, Dhofar province / Jabal al Qamar / W Al Mughsayl - Wádí / N 16.84497 E 53.68615 / 20-31.8.2012 / lgt. P. Kučera [w, p]" (LSCP).

YEMEN: 1 ภ, "YEMEN-W, Jabal Bura / NEE Al Hudaydah / 200-800m, 30.X.-1.XI. / N 14²', E $43^{\circ} 24^{\prime}$ / J. Halada lg., 2005 [w, p]" (NMPC).
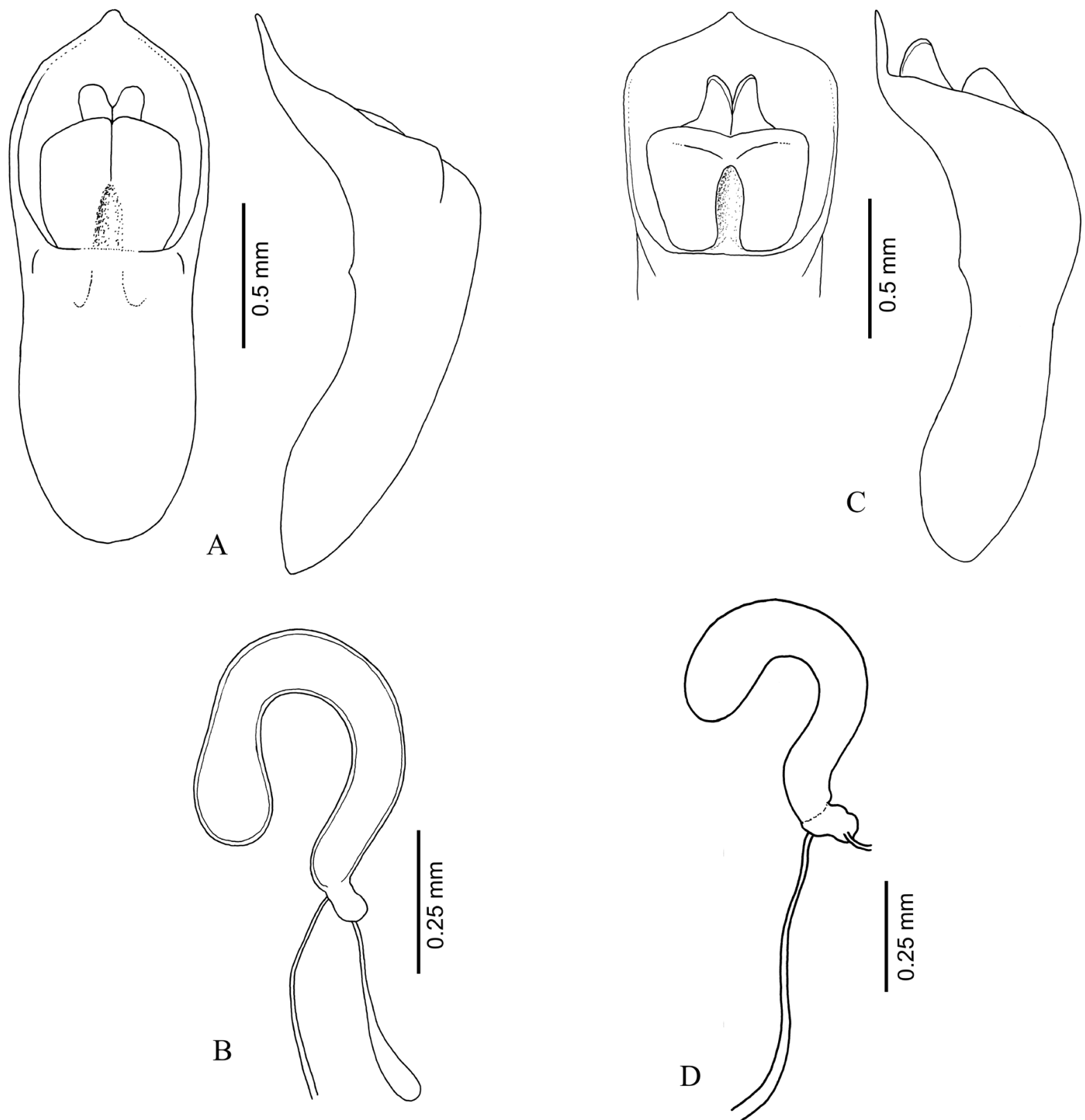

Fig. 10. A-B. Tituboea radeki Bezděk sp. nov. A. Aedeagus in dorsal and lateral views. B. Spermatheca. C-D. T. arabica (Olivier, 1808). C. Aedeagus in dorsal and lateral views. D. Spermatheca. 


\section{Type locality}

OMAN: Al Mughsayl env.

\section{Description}

Body LENGTH. ふふぇ: 6.7-8.9 mm (holotype $8.1 \mathrm{~mm}$ ),,$+7.3 \mathrm{~mm}$.

Male (holotype, Fig. 9A)

Colouration. Body orange, apices of mandibles black, most of metasternum blackish, abdominal ventrites I-III infuscate, each elytron with three black spots (one on humeral callus, second subscutellar, third large, transverse, behind elytral midlength), apical halves of claws darkened (Fig. 9A).

HEAD. Mandibles small (Fig. 9B). Labrum with widely rounded anterior angles and slightly concave anterior margin, surface with several irregular large setigerous punctures on the surface, additional setae accumulated along anterior margin (particularly at sides). Clypeus with widely shallowly V-shaped anterior margin, surface transversely impressed, small setigerous punctures accumulated laterally. Frons wide, 2.77 times as wide as diameter of eye, surface covered with an irregular mixture of smaller and larger punctures and short setae, in middle distinctly impressed, with furrow along inner eye margin. Frons not separated from vertex. Vertex lustrous, densely covered with small punctures and short pale setae, with indistinct median line. Antennae short, 0.19 times as long as body, antennomere I club-shaped, II small, subglobular, III very small, antennae shortly serrated from antennomere IV, antennomeres V-X wider than long.

Pronotum. Glabrous, lustrous, strongly transverse, 1.97 times as wide as long, widest at basal quarter, moderately convex, covered with mixture of dense small feeble punctures and sparse larger punctures. Anterior margin shallowly concave, lateral margins rounded, posterior margin nearly straight but shallowly bisinuate in scutellar area. Anterior angles obtusangulate with rounded tip, posterior angles widely rounded. All margins thinly bordered, border in middle part of anterior margin feeble but visible. Posterior angles slightly elevated above elytral base.

Scutellum. Scutellum subtriangular with rounded tip, in middle with elevated impunctate line, basal half punctate and covered with setae, towards apex becoming impunctate and almost glabrous, scutellar apex elevated upon elytral level.

ElYTRA. Elytra short, subcylindrical, 0.67 times as long as body, 1.50 times as long as wide at humeral part, glabrous, lustrous, densely covered with small confused punctures, disappearing at elytral apices, here and there tending to irregular puncture rows and 3-4 indistinct impunctate ribs. Basal margin with complete thin border forming narrow elevated keel. Epipleura impunctate, glabrous, wide in anterior fifth, suddenly narrowed and disappearing in anterior $1 / 4$ of elytral length. Lateral margin of elytra widely concave in lateral view.

Legs. Protarsi moderately enlarged, protibiae moderately prolonged. Protarsomere I short and robust, 1.67 as long as broad, almost parallel, as wide as II, protarsomere II elongate subtriangular, only slightly shorter than I, length ratios of protarsomeres I-IV equal to 10-9-9-11. Metatarsi short and thin, length ratios of metatarsomeres I-IV equal to 9-6-6-9. Claws simple.

Genitalia. Aedeagus 2.6 times as long as wide, apical part rounded towards to triangular apex, in lateral view apex only slightly and gradually bent upwards (Fig. 10A). Ventral side without imressions.

VARIABILITY. Pronotum 1.89-2.00 times as wide as long. One paratype with subscutellar elytral spot absent. 
BEZDĚK J., Clytrini of the Eastern Mediterranean, the Near East and the Arabian Peninsula

\section{Female}

Tarsomeres thinner than in male. Pronotum 1.90 times as wide as long. Spermatheca: cornu U-shaped with slightly wider apex, nodulus small, elongate, proximal spermathecal duct 0.9 times as long as cornu (Fig. 10B).

\section{Distribution}

Oman, Yemen.

Saudiclytra wittmeri (Medvedev, 1979)

Fig. 11

Antipa wittmeri Medvedev, 1979: 296 (original description).

Saudiclytra spinifemorata Medvedev, El Torkey \& Al Dhafer, 2014: 7 (original description), syn. nov.

\section{Material examined}

Type material

SAUDI ARABIA: 1 §, holotype of Saudiclytra wittmeri, "Abha Gizan km 28 [p] 22.4 [h] / Wadi Ad Dilla 700 m [w, p] // Saudi Arab. 1976 / Wittmer, Büttiker [w, p] // Holotypus [r, p] // Antipa 19 [p] 77 / wittmeri $\mathrm{m}$. [h] / L. Medvedev det. [w, p]" (NHMB).

SAUDI ARABIA: 1 , holotype of Saudiclytra spinifemorata, "Saudi Arabia, Baha, Wadhi / Turubah 14.V.2011 A:918 m / Sweeping Net / N: 20¹2.610' E: 41¹7.056’ / H. Al Fadly, A. El Torkey, M. / Sharaf \& H. Setyaningrum [w, p] // HOLOTYPUS [p] / Saudiclytra / spinifemorata $[\mathrm{h}] /$ L. Medvedev det [p] 2013 [r, h] // Saudiclytra spinifemorata / Medvedev, El Torkey \& Al Dhafer [w, p]" (KSMA).

\section{Other material}

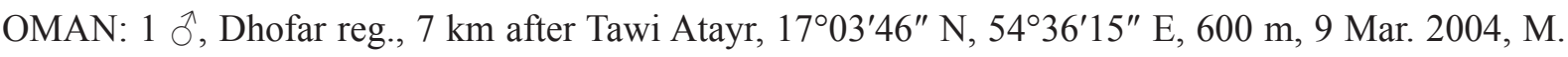

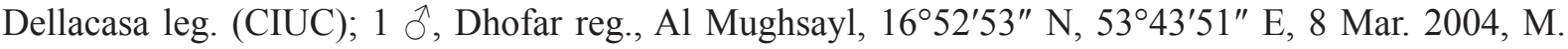
Dellacasa leg. (CIUC); 1 đ, Ad Dakhiliyah gov., near Subayb, 30 Mar. 2018, J. Pelikán leg. (JPCH);

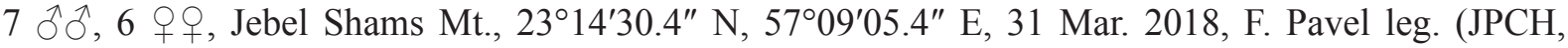
NMPC).

\section{Type localities}

Antipa wittmeri

SAUDI ARABIA: Abha Gizan km 28, Wadi Ad Dilla.

Saudiclytra spinifemorata

SAUDI ARABIA: Baha, Wadhi Turubah.

\section{Description of females}

Body LENGTH. 5.9-7.0 mm. Colouration (Fig. 11D): head black with orange underside, labrum, anterior margin of clypeus, mouthparts and small spot on posterior eye margin; pronotum pale orange with wide transverse black band, posterior and lateral margins with thin orange border, anterior margin with wider orange stripe; scutellum black, often with pale extreme apical margin; elytra orange with four small black spots (one at humeral callus, one subscutellar, two placed behind elytral midlength often connected forming transverse stripe); antennae black with orange antennomeres I-IV; legs completely orange; prosternum orange with black posterior parts, meso-, metasternum and abdomen black. 
HEAD. Labrum transverse with shallowly emarginated anterior margin, anterior angles rounded, surface dull, laterally covered with several large setigerous puncture bearing long setae. Clypeus and anterior part of head lustrous with sparse small punctures bearing pale setae, anterior clypeal margin with shallow wide V-shaped emargination. Frons and vertex semi-opaque with larger and denser puncture bearing longer setae more or less covering the surface. Frons slightly impressed, 2.8 times as wide as diameter of eye. Vertex moderately convex, in middle with longitudinal impressed and almost glabrous line. Vertex and frons separated by impressed line. Antennae short, 0.23 times as long as body, length ratios
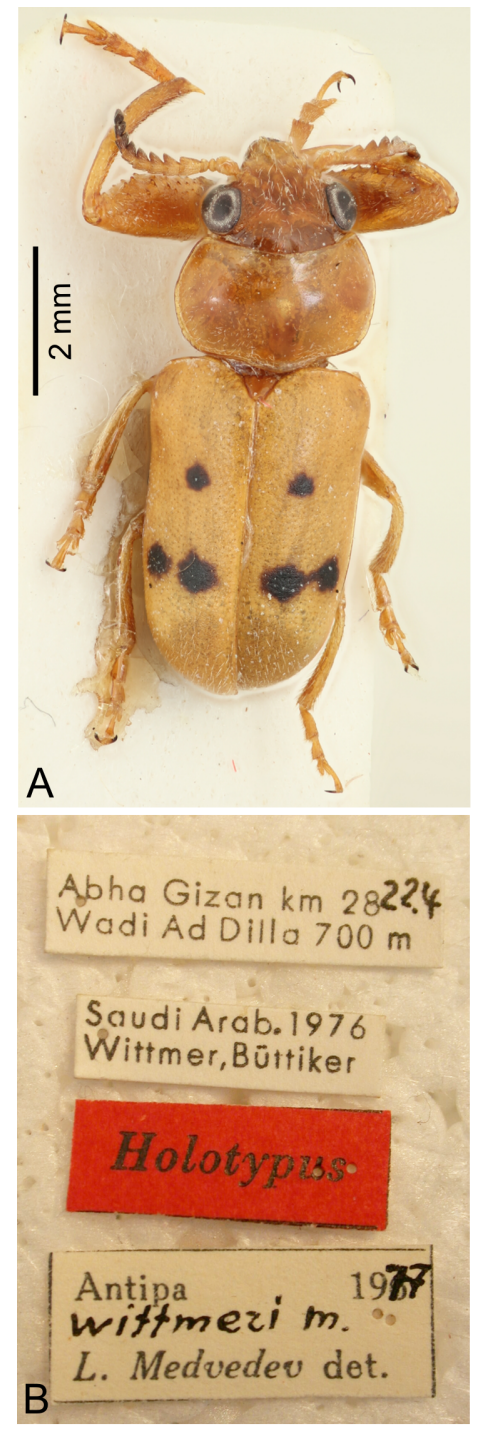
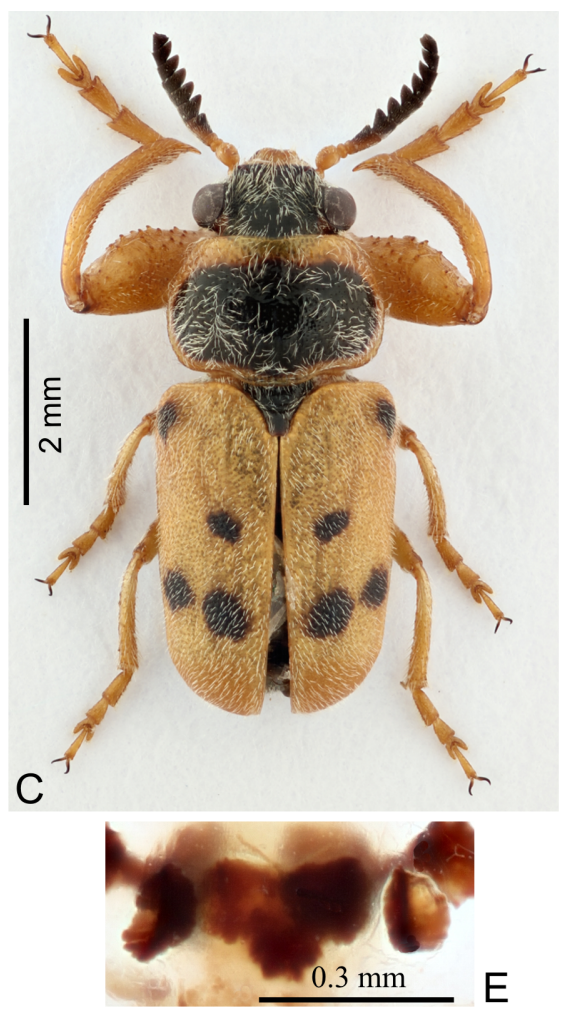

D
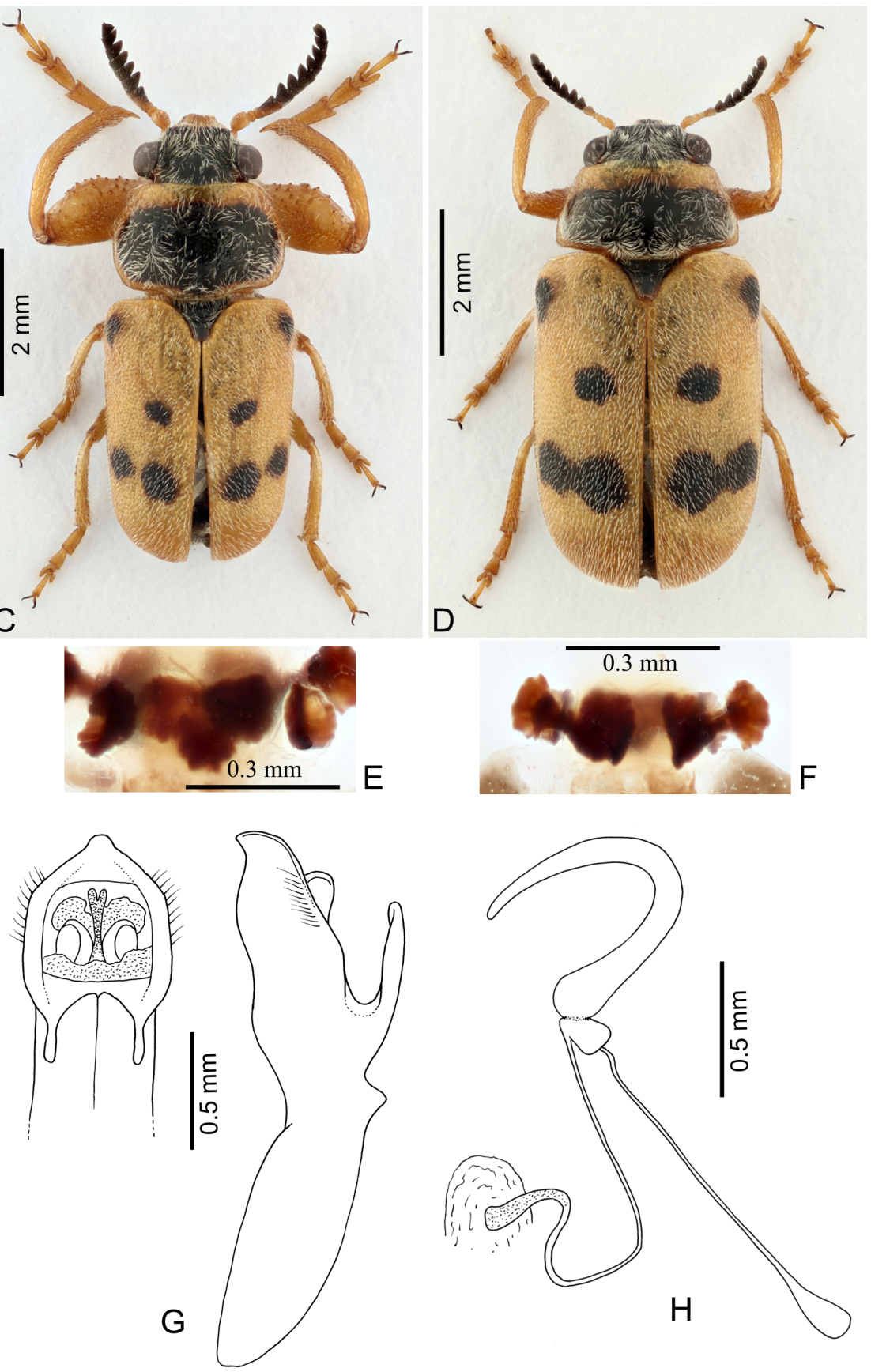

Fig. 11. Saudiclytra wittmeri (Medvedev, 1979). A. Holotype, Ô, $7.5 \mathrm{~mm}$ (NHMB). B. Labels of

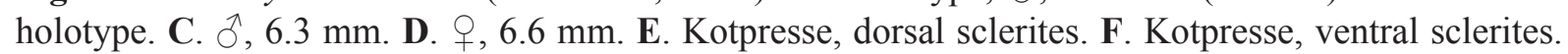
G. Aedeagus in dorsal and lateral views. H. Spermatheca. 
of antennomeres I-XI equal to 11-5-4-6-7-7-6-6-6-6-8, antennomere I club-shaped, II subglobular, III very small, IV shortly elongate, antennae serrated from antennomere V.

Pronotum. Pronotum lustrous, transverse, 1.67 times as wide as long, covered with small punctures and long pale setae, in middle with perpendicular more or less glabrous line. Anterior margin widely shallowly concave, lateral margins rounded with anterior parts straight and convergent anteriorly, posterior margin moderately rounded and moderately thickened in scutellar area. Lateral and posterior margins narrowly bordered (border slightly wider in posterior angles), anterior margin bordered only in lateral quarters. Anterior angles obtusangulate, posterior angles widely rounded, slightly elevated but not upon elytral level.

ScutelLum. Scutellum subtriangular with transversely cut tip and slightly concave lateral margins, covered with small punctures and short setae, punctation and setae disappearing towards tip, in basal part with indistinct perpendicular glabrous line, scutellar apex elevated upon elytral level.

ELYTRA. Elytra dull, semicylindrical, slightly convergent posteriorly, 0.71 as long as body, 1.4 times as long as wide, covered with very dense confused small punctures and dense short pale setae. Basal margin from humeral callus to base of scutellum with elevated swollen keel, highest in middle, basal elytral border elevated upon pronotum level. Epipleura narrow, visible in basal quarter, then disappearing, covered with sparse setae, nearly impunctate. Lateral margin of elytra moderately concave in lateral view.

Protarsomeres. Protarsomeres I and II subtriangular, narrow. Length ratios of protarsomeres I-IV equal to 9-6-7-10, of metatarsomeres I-IV equal to 9-6-4-9. Claws narrow, simple.

SpermatheCA. (Fig. 11H). Cornu U-shaped, thin, apical part gradually narrowed to apex, basal part slightly wider. Nodulus small, cylindrical. Spermathecal duct twice as long as cornu, proximal half very thin and straight, distal half twice curved with wider terminal part. Kotpresse as in Fig. 11E-F.

\section{Sexual dimorphism}

Fore legs of females are not prolonged. Small denticles on profemora are less developed in females compared to well-developed denticles in males.

\section{Distribution}

Saudi Arabia (Medvedev 1979; Medvedev et al. 2014). Newly recorded from Oman.

\section{Comments}

Medvedev et al. (2014) gave only superficial characters, such as the colouration of dorsum and the intensity of punctation on the head, pronotum and elytra to separate Saudiclytra spinifemorata and Saudiclytra wittmeri. All these characters are very variable in many species of Clytrini occurring in arid areas. Also the drawing of the aedeagus of Saudiclytra spinifemorata presented in the original description is inaccurate in comparison with the actual specimen. In reality, the aedeagus of Saudiclytra spinifemorata is of exactly the same shape as that of Saudiclytra wittmeri (Fig. 11G). Consequently, Saudiclytra spinifemorata is proposed as a new synonym of Saudiclytra wittmeri.

In one of my previous papers (Bezděk 2016) I tentatively accepted the placement of Antipa wittmeri in the genus Tituboea Lacordaire, 1848. At that time I was not aware of Saudiclytra Medvedev, E1 Torkey \& Al Dhafer, 2014. The main diagnostic characters of Saudiclytra are propleura densely covered with long setae, short and strongly transverse second and third antennomere in male, numerous ventral 
spines on anterior femora and unusual form of the aedeagus, shortly pubescent epipleura and the unusual structure of the aedeagus (Fig. 11G).

The colouration is variable throughout the distributional area (Fig. 11A, C-D). All the specimens from Oman represent darker aberrations with the black pattern more developed (particularly on the pronotum). The holotype of Saudiclytra wittmeri is the palest aberration, with the black pattern reduced to small spots on the elytra.

\section{Faunistics and comments}

Afrophthalma antipaeformis Medvedev, 1993

\section{Material examined}

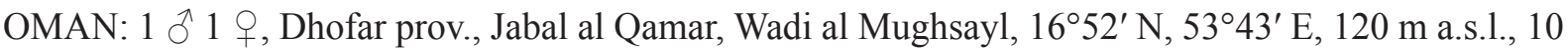
Apr. 2013, P. Kučera leg. (LSCP).

YEMEN: $1 \partial^{7}$, Wadi Zabid, E of Zabid, $1^{\circ} 09^{\prime} \mathrm{N}, 43^{\circ} 31^{\prime}$ E, 325 m a.s.1., 22 Mar. 2007, P. Kabátek leg.

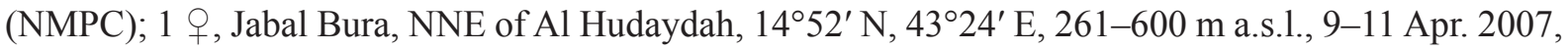
P. Kabátek leg. (NMPC).

\section{Distribution}

Saudi Arabia (Regalin \& Medvedev 2010b). New species for Oman and Yemen.

\section{Afrophthalma arabica (Bryant, 1957)}

Fig. 12

\section{Material examined}

\section{Holotype}

YEMEN: 1 , , "Type [round white label with red collar, p] // W. ADEN PROT. / Jebel Jihaf, / Wadi Lejij. / ca. 7,000 ft. / 1.x.1937. [w, p] // B. M. Exp. to / S. W. Arabia / H. Scott \& / E. B. Britton / B. M. 1938246. [w, p] // Gynandrophthalma / arabica / Bryant. [h] / G. E. Bryant det. 195 [h] 6 [w, h]” (BMNH).

\section{Paratype}

YEMEN: 2 우, "from edges of / terraced fields. [w, p] // W. ADEN PROT. / Jebel Jihaf, / Wadi Lejij. / ca. 7,000 ft. / 29.ix.1937. [w, p] // B. M. Exp. to / S. W. Arabia / H. Scott \& / E. B. Britton / B. M. 1938-246. [w, p] // SYNTYPE / Smaragdina / arabica Bryant [w, p]” (BMNH).

\section{Other material examined}

OMAN: 1 đ̂, Darbaat, 18-21 Sep. 2003, R. Červenka leg. (JBCB); Taqah env., ca 270-300 m a.s.1., 18-19 Oct. 2005, R. Červenka leg. (JBCB); Dhofar, Wadi Nashib, 1-3 Sep. 2007, Z. Košt’ál leg. (NMPC); 2 오오. Dhofar, Jabal al Qamar, $15 \mathrm{~km}$ W of Al Mughsayl, $16.85591^{\circ} \mathrm{N}, 53.72375^{\circ} \mathrm{E}, 450 \mathrm{~m}$ a.s.l., 26 Sep. 2011, P. Kučera leg. (LSCP); 1 + , Dhofar, Jabal al Qamar, $5 \mathrm{~km} \mathrm{~N}$ of Dhalqut, $16.72291^{\circ} \mathrm{N}$

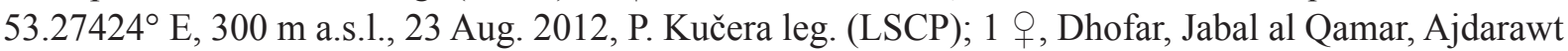
env., Ra’s Sajir-Wádí, 750 m a.s.1., 24 Sep. 2011, P. Kučera leg. (LSCP); 1 q, Dhofar, Jabal Samhán,

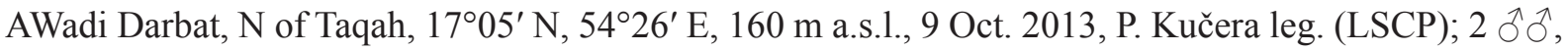
1 , Dhofar, Jebel Samhan, 900-1200 m a.s.1., 23-25 Sep. 2003, S. Jakl leg. (JPCH).

YEMEN: 1 §, 1 क, Haraz Mts., S slope of Al Ilan Mt., 2600 m a.s.1., 23 Jun. 2010, V. Hula and J. Niedobová leg. (JBCB). 


\section{Comments}

The elytral colour pattern of Afrophthalma arabica is variable. The female holotype depicted in the original description has a metallic stripe starting on the humeral callus, narrow in the anterior half and widened in the posterior half on each elytron (Fig. 12A). The anterior part of the metallic stripe is missing in most of the examined specimens (Fig. 12C) including two female paratypes. On the contrary, two examined specimens from Yemen have an extended metallic pattern with only the sutural stripe orange (Fig. 12D). The males of pale and dark forms were dissected, and their aedeagi are exactly the same (Fig. 12E).

\section{Distribution}

Oman, Saudi Arabia, Yemen (Regalin \& Medvedev 2010b).
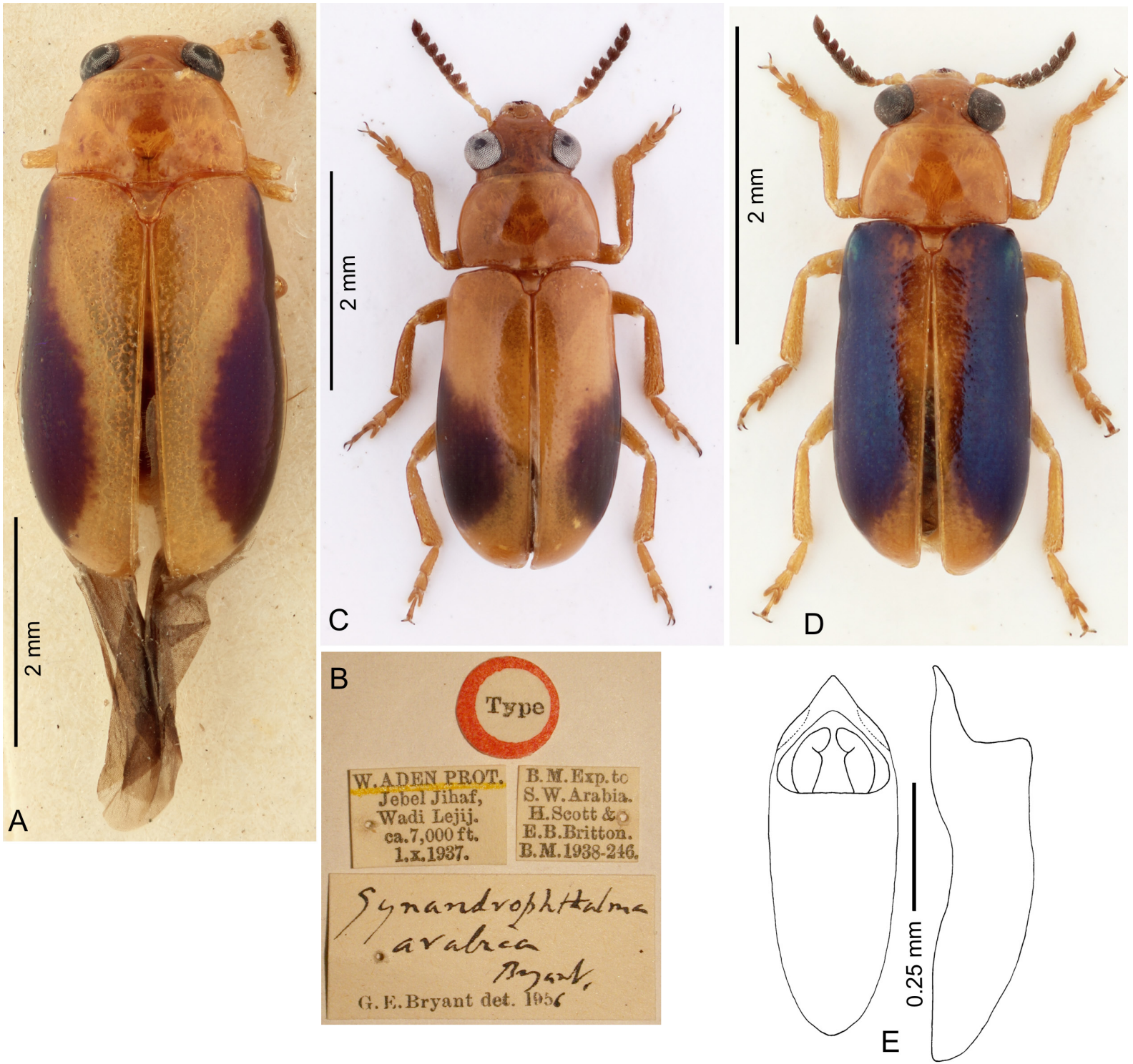

Fig. 12. Afrophthalma arabica (Bryant, 1957). A-B. Holotype, $q, 4.5 \mathrm{~mm}(\mathrm{BMNH})$. A. Dorsal view.

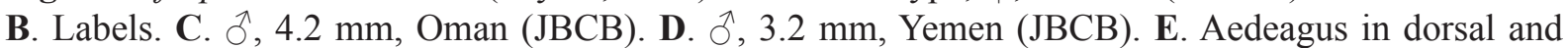
lateral views. 
Cheilotoma (Cheilotoma) musciformis musciformis Goeze, 1777

\section{Material examined}

GREECE: 1 \%, Central Greece, Phthiotis, Parnassus, Saranduli, 1200 m a.s.1., 4 Jun. 2005, F. Angelini leg. (NMPC); 1 ㅇ, West Macedonia, Florina, 1200-1350 m a.s.1., 11 Jun. 2007, F. Angelini leg. (NMPC); 1 ô, Thessaly, Larissa, Ossa Mts., 1500 m a.s.1., 1 Jun. 2006, V. Skoupý leg. (NMPC); 2 qq, Thessaly, Trikala, Amaranto, 30 km E of Kalabaka, 1600 m a.s.1., 18-19 Jun. 2006, Bolm leg. (NMPC).

\section{Distribution}

Central, southern and eastern Europe, Turkey, eastern Siberia, Kazakhstan, Mongolia (Regalin \& Medvedev 2010b). Confirmed occurrence in Greece.

\section{Comments}

Regalin \& Medvedev (2010b) catalogued Cheilotoma musciformis from Greece without concrete data. As far as I know, the above listed specimens are the first concrete specimens published from Greece.

Clytra novempunctata Olivier, 1808

\section{Material examined}

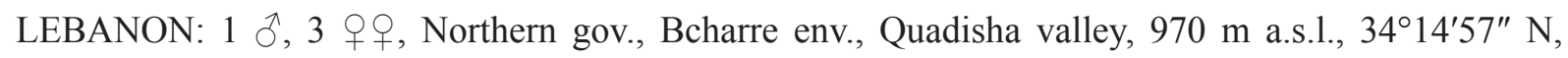
3558'34" E, 27 May 2015, Boustani, Márkus, Németh and Rehayem leg. (HNHM); 2 $\widehat{\partial}$, Northern gov., Tanourine env., 2 km N of Harissa, Tanourine Cedars Nat. Res., 1750 m a.s.1., 34 $12^{\prime} 34^{\prime \prime}$ N, 3555'45" E, 23 May 2015, O. Akiki, M. Boustani, A. Márkus, N. Nemer, T. Németh, M. Rehayem and W. Yaminne leg. (HNHM).

\section{Distribution}

Widely distributed in South and East Europe, the Caucasus, Egypt, Cyprus, Turkey, Turkmenistan, and the Near East (Regalin \& Medvedev 2010b). New species for Lebanon.

Clytra quadripunctata quadripunctata (Linnaeus, 1758)

\section{Material examined}

GREECE: 1 ô, East Macedonia and Thrace, Xanthi, Petrochori, 12 May 2001, J. Schneider leg. (NMPC).

\section{Distribution}

Widely distributed in Palaearctic Region (Regalin \& Medvedev 2010b). Confirmed occurrence in Greece.

\section{Comments}

Regalin \& Medvedev (2010b) listed Clytra quadripunctata quadripunctata from Greece probably based on the specimens of Clytra appendicina Lacordaire, 1848 published by Rozner \& Rozner $(2008,2014)$. Clytra appendicina is often treated as a synonym of Clytra quadripunctata quadripunctata but also as its subspecies or as valid species. The above mentioned specimen confirms the occurrence of true Clytra quadripunctata quadripunctata in Greece. 
BEZDĚK J., Clytrini of the Eastern Mediterranean, the Near East and the Arabian Peninsula

Coptocephala destinoi Fairmaire, 1884

\section{Material examined}

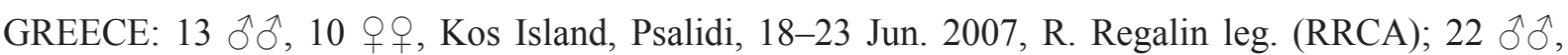
18 우, Samos Island, Marathokambos, Votsalakia, 20-27 Jun. 2006, R. Regalin leg. (RRCA); $7 \widehat{\delta} \widehat{\partial}$, 2 우오, Samos Island, Votsalakia env., 11-20 Jun. 2007, K. Schön leg. (NMPC).

\section{Distribution}

Caucasus, Turkey, Greece (Kos, Samos), Near East (Regalin \& Medvedev 2010b).

\section{Comments}

Regalin \& Medvedev (2010b) catalogued Coptocephala destinoi from Greek islands Kos and Samos without concrete data. The voucher specimens are listed above.

Coptocephala fallaciosa Fairmaire, 1884

\section{Material examined}

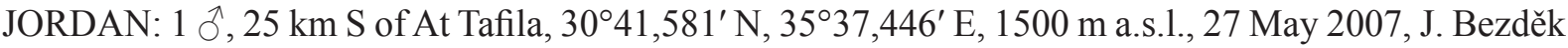

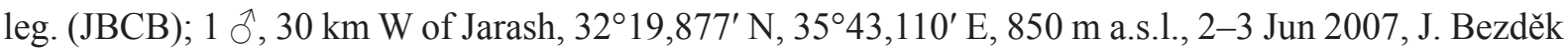
leg. (JBCB); $1 \mathrm{o}^{\top}, 15 \mathrm{~km} \mathrm{~S}$ of Madaba, $31^{\circ} 40.8^{\prime} \mathrm{N}, 35^{\circ} 41.3^{\prime} \mathrm{E}, 760 \mathrm{~m}$ a.s.1., rock steppe, 28 Apr. 2006,

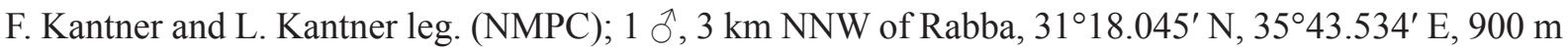
a.s.1., 27 May 2007, F. Kantner and L. Kantner leg. (NMPC).

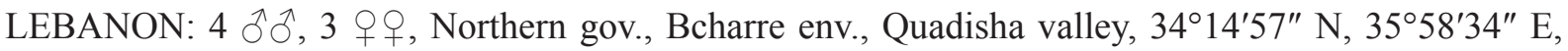
970 m a.s.1., 23 Jun. 2016, A. Kotán, T. Németh and W. Yammine leg. (HNHM); 1 , , Northern gov.,

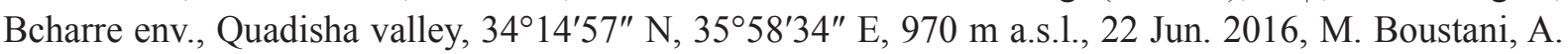
Kotán, P. Nemes, T. Németh and W. Yammine leg. (HNHM); 1 q, Northern gov., Tannourine env., 2 km

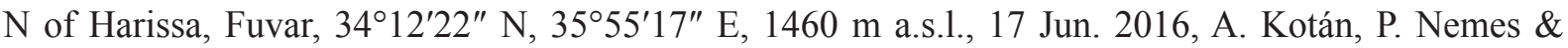

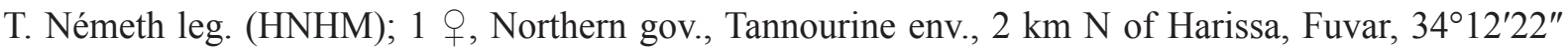
N, 3555'17" E, 1460 m a.s.1., 27 Jun. 2016, A. Kotán, P. Nemes and T. Németh leg. (HNHM); 1 q, Northern gov., Tannourine env., $2 \mathrm{~km}$ N of Harissa, Tannourine Cedars Nature Reserve, $1750 \mathrm{~m}$ a.s.1., 6 May 2016, N. Nemer leg. (HNHM).

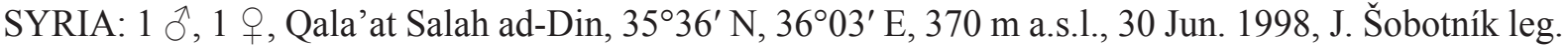
(JBCB).

\section{Distribution}

Israel, Turkey (Regalin \& Medvedev 2010b). New species for Jordan, Lebanon and Syria.

\section{Comments}

Previous records from Syria (Fairmaire 1884; Pic 1942) refer to Akbes, situated in Turkey today, and to the type locality Syria of Coptocephala fallaciosa var. tambei Pic, 1942 synonymised with Coptocephala destinoi by Bezděk \& Regalin (2015).

Coptocephala rubicunda rubicunda (Laicharting, 1781)

\section{Material examined}

GREECE: 1 đ̂, 1 \&, Central Macedonia, Chalkidiki, Sikia, Jul. 1991, V. Novák leg. (MZCK). 


\section{Distribution}

Middle and South Europe (Regalin \& Medvedev 2010b). New species for Greece.

Coptocephala scopolina scopolina (Linnaeus, 1767)

\section{Comments}

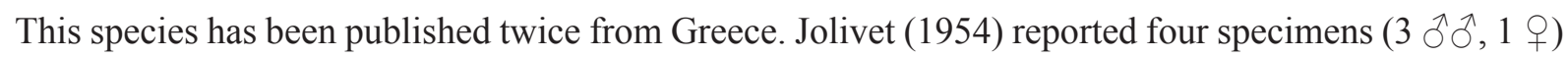
deposited in ISNB, and I was able to examine them. All three males (from Zagora and Koukouvitza) belong to Coptocephala hellenica Warchałowski, 1991, and the female from Litochoro is Macrolenes dentipes (Olivier, 1808). Rozner \& Rozner (2014) published Coptocephala scopolina as new for Greece based on one female. The voucher specimen, now deposited in HNHM, was examined and is undoubtedly a female of Coptocephala hellenica. Consequently, Coptocephala scopolina scopolina is deleted from the fauna of Greece.

Coptocephala simillima Lodewyckx, 1995

\section{Material examined}

ARMENIA: 1 ô, Khosrov reserve, 21 Jul. 1992, M. Kalashian leg. (JBCB); 1 đ, Erevan env., valley of Razdan river, 7 Jun. 1988, J. Strejček leg. (NMPC).

TURKEY: 1 đ 1 †, Ilgaz Dagi, 7-9 Aug. 1996, S. Mihulka leg. (JBCB).

\section{Distribution}

Turkey (Regalin \& Medvedev 2010b). New species for Armenia.

Labidostomis brevipennis Faldermann, 1837

\section{Material examined}

SYRIA: 1 q, von Bodemeyer leg. (NMPC).

\section{Distribution}

Caucasus, Turkey, Iran, Iraq (Regalin \& Medvedev 2010b). Confirmed occurrence in Syria.

\section{Comments}

Regalin \& Medvedev (2010b) listed Labidostomis brevipennis from Syria without any concrete data. The above mentioned female confirms the occurrence in Syria.

\section{Labidostomis cyanicornis (Germar, 1822)}

\section{Material examined}

GREECE: 1 ð, East Macedonia and Thrace, Drama, Kato Nevrokopi, 4 Jun. 2007, Angelini leg. (NMPC).

\section{Distribution}

Europe except northern part, Turkey, Siberia, Kazakhstan, Mongolia (Regalin \& Medvedev 2010b). New species for Greece. 
BEZDĚK J., Clytrini of the Eastern Mediterranean, the Near East and the Arabian Peninsula

Labidostomis karamanica Weise, 1900

\section{Material examined}

GREECE: 7 ふð, 3 q , Rhodes Isl., Emponas env., 400 m a.s.l., 7 May 1996, R. Borovec leg. (NMPC); $3 \widehat{\jmath}$, Rhodes Island, Koutsoútis near Emponas, 400 m a.s.l., 7 May 1996, R. Borovec leg. (NMPC).

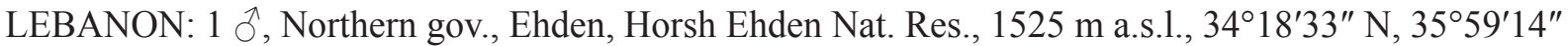
E, 21 May 2015, M. Boustani, A. Márkus and T. Németh leg. (HNHM); 2 우, Northern gov., Bcharre env., $1 \mathrm{~km}$ E of Ariz, Horsh Arz el-Rab, ancient Cedrus forest, 34¹4'33" N, 3602'59" E, $1900 \mathrm{~m}$ a.s.1., 20 May 2015, A. Márkus and T. Németh leg. (HNHM); 2 $\partial^{\lambda}, 1$ \& , Northern gov., Bcharre env., Quadisha valley, $34^{\circ} 14^{\prime} 57^{\prime \prime}$ N, 3558'34" E, 970 m a.s.l., A. Kotán, P. Nemes, T. Németh and C. Tanios leg. (HNHM).

\section{Distribution}

Cyprus, Israel, Syria, Turkey (Regalin \& Medvedev 2010b), Iran (Ghahari \& Jedryczkowski 2012). New species for Greece (Rhodes Island) and Lebanon.

Labidostomis propinqua Faldermann, 1837

\section{Material examined}

SERBIA: 1 + , Resavica, 30 May 1988, L. Kantner leg. (NMPC).

\section{Distribution}

Southeastern Europe, Turkey, Near East, Iran, Crimea, southern Russia, Caucasus (Regalin \& Medvedev 2010b). New species for Serbia.

\section{Lachnaia sexpunctata (Scopoli, 1763)}

\section{Material examined}

LEBANON: 1 q, Northern gov., Bcharre env., Quadisha valley, $970 \mathrm{~m}$ a.s.1., 34 ${ }^{\circ} 14^{\prime} 57^{\prime \prime} \mathrm{N}, 35^{\circ} 58^{\prime} 34^{\prime \prime} \mathrm{E}$, 27 May 2015, Boustani, Márkus, Németh and Rehayem leg. (HNHM); 1 q, Northern gov., Tanourine

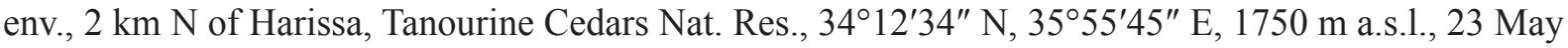
2015, O. Akiki, M. Boustani, A. Márkus, N. Nemer, T. Németh, M. Rehayem and W. Yaminne leg.

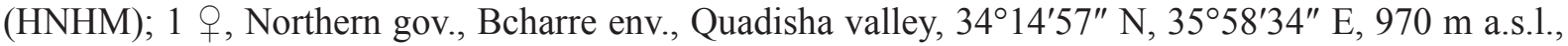
23 Jun. 2016, Kotán, Németh and Yammine leg. (HNHM); 3 우, Northern gov., Tannourine env., 2 km

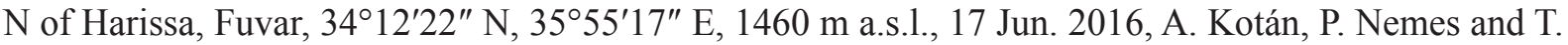
Németh leg. (HNHM).

SYRIA: 1 đ, 1 \&, Latakia prov., Slunfeh, macchia-oak forest, 4 Jun. 2010, A. Kotán, E. Mizsei, T. Németh and N. Rahmé leg. (HNHM).

\section{Distribution}

Widely distributed in Middle, South and East Europe, Turkey, Israel (Regalin \& Medvedev 2010b). New species for Lebanon and Syria.

Smaragdina xanthaspis (Germar, 1824)

\section{Material examined}

SYRIA: 1 ð, 1 $\uparrow, 10$ km SSW of Masyaf, 2-3 Jun. 2009, F. Houška leg. (JBCB). 


\section{Distribution}

Widely distributed in Europe, Turkey, Caucasus and Near East (Regalin \& Medvedev 2010b). Confirmed occurrence in Syria.

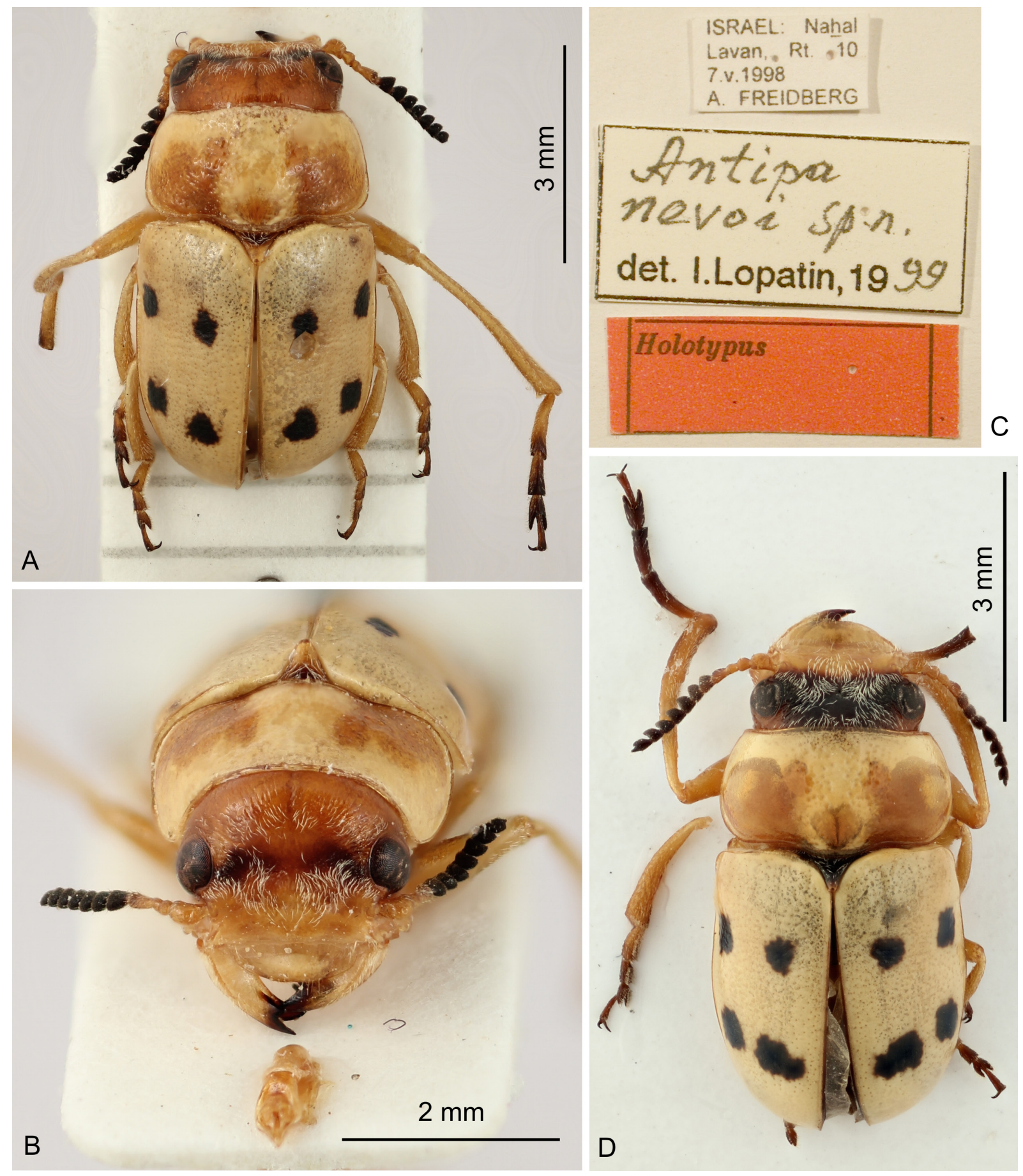

Fig. 13. Tituboea nevoi Lopatin \& Chikatunov, 2001. A-C. Holotype, ô, $6.2 \mathrm{~mm}$ (TAU). A. Dorsal view. B. Frontal view. C. Labels. D. $\widehat{\jmath}, 6.3 \mathrm{~mm}$, Libya (JBCB). 


\section{Comments}

Although Smaragdina xanthaspis is listed from Syria in some publications (e.g., Lopatin et al. 2003; Regalin \& Medvedev 2010b), I do not know any concrete published specimens. The above mentioned specimens confirm the occurrence in Syria.

Tituboea nevoi Lopatin \& Chikatunov, 2001

Fig. 13

\section{Material examined}

LIBYA: 1 đ, Misurata, 7 May 1988, without collector's name (JBCB).

\section{Distribution}

Israel (Lopatin \& Chikatunov 2001; Lopatin et al. 2003). New species for Libya.

\section{Comments}

The specimen from Libya (Fig. 13D) was compared with the holotype (Fig. 13A-C).

\section{Discussion}

Taking into consideration the present paper, the Old World genus Tituboea Lacordaire, 1848 contains about 75 species with the majority of the 55 species distributed in the Palaearctic region (Regalin \& Medvedev 2010b; Bezděk \& Batelka 2011; Bezděk 2012; Bezděk \& Regalin 2015). The classification of some species in Tituboea, however, requires verification (e.g., Regalin 1997). The taxonomy of Tituboea is complicated by the considerable variability of colouration and sexually dimorphic characters as well as local populations often being described as varieties or species (Bezděk \& Regalin 2015). Despite these problems, the increasing number of Tituboea species is expected particularly in arid areas of the western Palaearctic.

The exclusively Palaearctic genus Labidostomis Chevrolat, 1936 comprises about 95 species (Warchałowski 2004; Guskova 2006; Lopatin \& Nesterova 2007; Regalin \& Medvedev 2010b; Bezděk \& Regalin 2017; Bezděk 2018). The taxonomically difficult species complexes are step by step revised based on the examination of the primary type material and the study of the internal aedeagus sclerites (Bezděk \& Regalin 2017; Bezděk 2018).

Although the sclerites of the internal sac of the aedeagus are frequently studied in many families of Coleoptera, they can be found only occasionally in modern taxonomical literature on Chrysomelidae (for example, for Criocerinae: Tishechkin et al. (2011); Bezděk \& Baselga (2015); for Galerucinae: Kortenhaus \& Wagner (2010); Hazmi \& Wagner (2013); Lee \& Bezděk (2013); Bezděk \& Lee (2014); Wagner (2016); for Cryptocephalinae: Leonardi \& Sassi (2001); Sassi (2014)). In Clytrini, the sclerites of the internal sac were examined only sporadically in South American genera (Agrain et al. 2007; Agrain 2013), in the genera Lachnaia Chevrolat, 1836 (Baselga \& Ruiz-García 2007) or Labidostomis Chevrolat, 1836 (Bezděk \& Regalin 2017; Bezděk 2018). In the future, a comprehensive study of the aedeagus sclerites could help to resolve many problems in taxonomically difficult genera such as Coptocephala Chevrolat, 1836, Clytra Laicharting, 1781, Smaragdina Chevrolat, 1836 or Aetheomorpha Lacordaire, 1848.

\section{Acknowledgments}

I would like to thank all the curators and colleagues listed above for giving me the opportunity to study their collections. Thanks are due also to Nabil Nemer (Holy Spirit University of Kaslik) and Charbel 
Tawk (Committee of Cedar Forest Friends, Bcharre, Lebanon) for the organisation of the expedition during which the holotype of Labidostomis bcharrensis Bezděk sp. nov. was collected, and to the collectors Mira Boustani, Attila Kotán, Petra Nemes, Tamász Németh, Martine Rehayem, Challitah Tanios and Wael Yammine. The study of specimens in BMNH and MNHN was supported from the Synthesys Project GB-TAF-6425 and FR-TAF-3479 (http://www.synthesys.info/) financed by the European Community-Research Infrastructure Action under the Seventh Framework Programme.

\section{References}

Agrain F.A. 2013. A taxonomic review of the genus Megalostomis Chevrolat (Coleoptera, Cryptocephalinae, Chrysomelidae). Zootaxa 3748: 1-109. https://doi.org/10.11646/zootaxa.3748.1.1

Agrain F.A., Roig-Juñent S. \& Domínguez M.C. 2007. Taxonomic revision and preliminary phylogenetic analysis of the subgenus Megalostomis (Scaphigenia) Lacordaire (Coleoptera: Chrysomelidae). Insect Systematics \& Evolution 38: 335-359. https://doi.org/10.1163/187631207788754402

Baselga A. \& Ruiz-García J. 2007. Revision of the Lachnaia tristigma (Lacordaire, 1848) species-group (Coleoptera: Chrysomelidae) and description of a new species. Zootaxa 1630: 39-46.

Bezděk J. 2012. Tituboea purcharti sp. nov., the first representative of Clytrini from Socotra Island (Coleoptera: Chrysomelidae: Cryptocephalinae). In: Hájek J. \& Bezděk J. (eds.) Insect biodiversity of the Socotra Archipelago. Acta Entomologica Musei Nationalis Pragae 52 (Suppl. 2): 395-401.

Bezděk J. 2016. Revision of the Clytra subfasciata species group (Coleoptera: Chrysomelidae: Cryptocephalinae: Clytrini). Zoology in the Middle East 62: 148-157. https://doi.org/10.1080/09397140.2016.1182772

Bezděk J. 2018. Revision of Labidostomis (Coleoptera: Chrysomelidae: Cryptocephalinae: Clytrini) with large united elytral spot from Iran and adjacent countries. Zootaxa 4457: 501-519. https://doi.org/10.11646/zootaxa.4457.4.1

Bezděk J. \& BaselgaA. 2015. Revision of western Palaearctic species of the Oulema melanopus group, with description of two new species from Europe(Coleoptera:Chrysomelidae:Criocerinae).Acta Entomologica Musei Nationalis Pragae 55: 273-304. Available from http://aemnp.eu/PDF/55_1/55_1_273.pdf [accessed 13 Nov. 2018].

Bezděk J. \& Batelka J. 2011. Order Coleoptera, family Chrysomelidae. Additions and description of a new species. In: van Harten A. (ed.) Arthropod fauna of the UAE 4: 250-273. Dar Al Ummah Printing, Publishing, Distribution \& Advertising, Abu Dhabi.

Bezděk J. \& Lee C.-F. 2014. Revision of Charaea (Coleoptera: Chrysomelidae: Galerucinae) from Taiwan. Zootaxa 3861: 1-39. https://doi.org/10.11646/zootaxa.3861.1.1

Bezděk J. \& Regalin R. 2015. Identity of species-group taxa of the Western Palaearctic Clytrini (Coleoptera: Chrysomelidae: Cryptocephalinae) described by Maurice Pic and Louis Kocher. Acta Entomologica Musei Nationalis Pragae 55 (Suppl.): 1-114. Available from http://aemnp.eu/archive/2015/55/s/ [accessed 13 Nov. 2018].

Bezděk J. \& Regalin R. 2017. A review of Labidostomis species similar to L. longimana from southeastern Europe with descriptions of two new species from Greece and Turkey (Coleoptera: Chrysomelidae: Cryptocephalinae: Clytrini). Zootaxa 4317: 321-337. https://doi.org/10.11646/zootaxa.4317.2.8

Fairmaire L. 1884. Liste des coléoptères recueillis par M. 1'Abbé David à Akbès (Asie Mineure) et description des espèces nouvelles. Annales de la Société entomologique de France, series 6, 4: 165-180. Available from https://biodiversitylibrary.org/page/32550281 [accessed 13 Nov. 2018]. 
BEZDĚK J., Clytrini of the Eastern Mediterranean, the Near East and the Arabian Peninsula

Ghahari H. \& Jedryczkowski W.B. 2012. A contribution to the knowledge of leaf beetles (Coleoptera: Chrysomelidae) from Arasbaran Biosphere Reserve and its neighboring areas (northwestern Iran). Acta Zoologica Bulgarica 64: 347-352.

Guskova E.V. 2006. New data on leaf-beetles (Coleoptera, Chrysomelidae) from the Mongolian Altai. Euroasian Entomological Journal 5: 303-306.

Hazmi I.R. \& Wagner T. 2013. Revision of Neolepta Jacoby, 1884 and related galerucines from the Oriental region, including descriptions of two new genera (Coleoptera: Chrysomelidae: Galerucinae). The Raffles Bulletin of Zoology 61: 73-95.

Horn W., Kahle I., Friese G. \& Gaedike R. 1990. Collectiones entomologicae. Ein Kompendium über den Verbleib entomologischer Sammlungen der Welt bis 1960. Teil II: 221-573. Akademie der Landwirtschaftswissenschaften der Deutschen Demokratischen Republik, Berlin.

Jolivet P. 1954. Mission E. Janssens et R. Tollet en Grèce (Juillet-août 1953). 3e note. Bulletin et Annales de la Société entomologique de Belgique 90: 287-289.

Katbeh-Bader A. \& Medvedev L.N. 2000. Contribution to the Chrysomelidae (Coleoptera) of Jordan. Russian Entomological Journal 9: 255-259.

Kortenhaus S. \& Wagner T. 2010. Revision of Ootheca Chevrolat, 1837 from tropical Africa redescriptions, descriptions of new species and identification key (Coleoptera: Chrysomelidae, Galerucinae). Zootaxa 2659: 1-52.

Lacordaire J.T. 1848. Monographie des coléoptères subpentamères de la famille des phytophages. Tome second. Mémoires de la Société royale des Sciences de Liége 5: I-VI, 1-890. Available from https://www.biodiversitylibrary.org/item/54930\#page/9/mode/1up [accessed 13 Nov. 2018].

Lee C.-F. \& Bezděk J. 2013. Revision of the genus Dercetina from Taiwan and their similar species, with description of a new species from Myanmar (Insecta, Chrysomelidae, Galerucinae). ZooKeys 323: 1-33. https://doi.org/10.3897/zookeys.323.5195

Leonardi C. \& Sassi D. 2001. Studio critico sulle specie di Cryptocephalus del gruppo hypochaeridis (Linné, 1758) e sulle forme ad esse attribuite (Coleoptera Chrysomelidae). Atti della Società Italiana di Scienze Naturali e del Museo Civico di Storia Naturale Milano 142: 3-96.

Lefèvre É. 1872. Monographie des clytrides d'Europe et du bassin de la Méditerranée. Annales de la Société entomologique de France, series 5, 2: 49-168, 313-396. Available from https://biodiversitylibrary.org/page/32514408 [accessed 13 Nov. 2018].

Lopatin I.K. 2002. New data on the taxonomy and distribution of leaf beetles in Israel (Coleoptera: Chrysomelidae). Zoosystematica Rossica 10 (2001): 379-380.

Lopatin I.K. \& Chikatunov V.I. 2001. Two new species of the genus Antipa (subgenus Tituboea) from Israel (Coleoptera: Chrysomelidae). Zoosystematica Rossica 9 (2000): 437-438.

Lopatin I.K. \& Nesterova O.L. 2007. A contribution on the taxonomy of the genus Labidostomis Germ. (Coleoptera, Chrysomelidae, Clytrinae). Euroasian Entomological Journal 6: 429-432.

Lopatin I.K., Chikatunov V.I. \& Pavlíček T. 2003. Catalogue of the beetles (Coleoptera) in Israel and adjacent areas: 3. Chrysomelidae (except Alticinae). Zoology in the Middle East 28: 87-112. https://doi.org/10.1080/09397140.2003.10637959

Medvedev L.N. 1962. New and interesting species of Palaearctic and Oriental Clytrinae (Coleoptera, Chrysomelidae). Annales Historico-Naturales Musei Nationalis Hungarici 54: 333-337.

Medvedev L.N. 1979. Insects of Saudi Arabia. Coleoptera: fam. Chrysomelidae, subfam. Clytrinae. Fauna Saudi Arabia 1: 295-298. 
Medvedev L.N. 1992. The Clytrinae (Coleoptera Chrysomelidae) of Israel. Russian Entomological Journal 1: 51-55.

Medvedev L.N. 1996. The Chrysomelidae of Arabia. Fauna of Saudi Arabia 15: 211-263.

Medvedev L.N., El Torkey A.M. \& Al Dhafer H.M. 2014. A new genus of Clytrinae from Saudi Arabia (Coleoptera: Chrysomelidae). Entomologische Zeitschrift 124: 7-9.

Pic M. 1942. Coléoptères du globe (Suite). L'Échange, Revue linnéenne 58: 5-8.

Regalin R. 1997. Le Tituboea descritte da Baly in "Phytophaga Malayana", 1865-1867 (Coleoptera, Chrysomelidae). Bollettino della Società Entomologica Italiana 129: 109-117.

Regalin R. \& Medvedev L.N. 2010a. New acts and comments. Chrysomelidae: Cryptocephalinae: Clytrini. In: Löbl I. \& Smetana A. (eds) Catalogue of Palaearctic Coleoptera. Chrysomeloidea 6: 7679. Apollo Books, Stenstrup.

Regalin R. \& Medvedev L.N. 2010b. Cryptocephalinae: Clytrini. In: Löbl I. \& Smetana A. (eds) Catalogue of Palaearctic Coleoptera. Chrysomeloidea 6: 564-580. Apollo Books, Stenstrup.

Romantsov P.V. 2017. New data on the leaf beetles of the subfamily Cryptocephalinae (Coleoptera: Chrysomelidae) from Middle Asia and Afghanistan. Entomological Review 97: 502-509. https://doi.org/10.1134/S0013873817040121

Rozner I. \& Rozner G. 2008. Data to the leaf-beetle fauna of Macedonia (Coleoptera: Chrysomelidae). Natura Somogyiensis 12: 111-131.

Rozner I. \& Rozner G. 2014. Data to the leaf-beetle fauna of Greece (Coleoptera: Chrysomelidae). Natura Somogyiensis 24: 81-98.

Sassi D. 2014. Taxonomic remarks, phylogeny and evolutionary notes on the leaf beetle species belonging to the Cryptocephalus sericeus complex (Coleoptera: Chrysomelidae: Cryptocephalinae). Zootaxa 3857: 333-378.

Tishechkin A.K., Konstantinov A.S., Bista S., Pemberton R.W. \& Center T.D. 2011. Review of the continental Oriental species of Lilioceris Reitter (Coleoptera, Chrysomelidae, Criocerinae) closely related to Lilioceris impressa (F.). ZooKeys 103: 63-83. https://doi.org/10.3897/zookeys.103.983

Wagner T. 2016. The Monolepta species of Namibia (Coleoptera, Chrysomelidae, Galerucinae). Entomologische Blätter 112: 407-442.

Walker F. 1871. List of Coleoptera collected by J.K. Lord, Esq. in Egypt, Arabia and near the African Shore of the Red Sea. E.W. Janson, London.

Waltl J. 1838. Beiträge zur Kenntniss der Coleopteren der Türkey. Isis von Oken 6: 449-472. Available from https://biodiversitylibrary.org/page/27396662 [accessed 13 Nov. 2018].

Warchałowski A. 2004. Labidostomis kantneri sp. nov. from Iran (Coleoptera: Chrysomelidae: Clytrinae). Annales Zoologici 54: 557-559. 
Manuscript received: 28 June 2018

Manuscript accepted: 20 September 2018

Published on: 4 December 2018

Topic editor: Gavin Broad

Desk editor: Alejandro Quintanar

Printed versions of all papers are also deposited in the libraries of the institutes that are members of the EJT consortium: Muséum national d'Histoire naturelle, Paris, France; Botanic Garden Meise, Belgium; Royal Museum for Central Africa, Tervuren, Belgium; Natural History Museum, London, United Kingdom; Royal Belgian Institute of Natural Sciences, Brussels, Belgium; Natural History Museum of Denmark, Copenhagen, Denmark; Naturalis Biodiversity Center, Leiden, the Netherlands; Museo Nacional de Ciencias Naturales-CSIC, Madrid, Spain; Real Jardín Botánico de Madrid CSIC, Madrid, Spain; Zoological Research Museum Alexander Koenig, Bonn, Germany. 